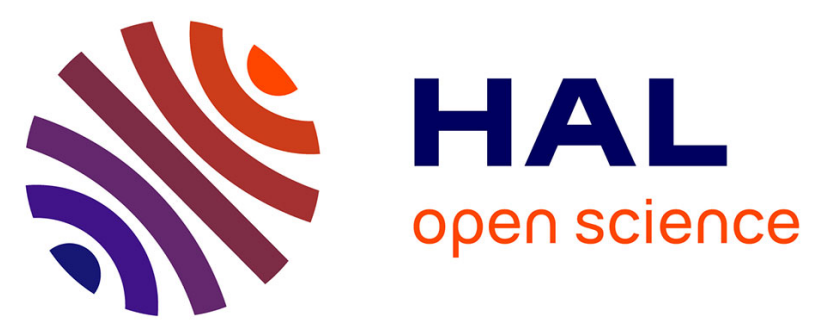

\title{
Spontaneous generation of ductile shear zones by thermal softening: Localization criterion, 1D to 3D modelling and application to the lithosphere
}

Daniel Kiss, Yuri Podladchikov, Thibault Duretz, Stefan M Schmalholz

\section{- To cite this version:}

Daniel Kiss, Yuri Podladchikov, Thibault Duretz, Stefan M Schmalholz. Spontaneous generation of ductile shear zones by thermal softening: Localization criterion, 1D to 3D modelling and application to the lithosphere. Earth and Planetary Science Letters, 2019, 519, pp.284-296. 10.1016/j.epsl.2019.05.026 . insu-02147766

\section{HAL Id: insu-02147766 \\ https://hal-insu.archives-ouvertes.fr/insu-02147766}

Submitted on 5 Nov 2019

HAL is a multi-disciplinary open access archive for the deposit and dissemination of scientific research documents, whether they are published or not. The documents may come from teaching and research institutions in France or abroad, or from public or private research centers.
L'archive ouverte pluridisciplinaire HAL, est destinée au dépôt et à la diffusion de documents scientifiques de niveau recherche, publiés ou non, émanant des établissements d'enseignement et de recherche français ou étrangers, des laboratoires publics ou privés. 


\title{
Spontaneous generation of ductile shear zones by thermal softening: localization criterion, $1 \mathrm{D}$ to $3 \mathrm{D}$ modelling and application to the lithosphere
}

\author{
Dániel Kiss ${ }^{\mathrm{a}, *}$, Yuri Podladchikov ${ }^{\mathrm{a}}$, Thibault Duretz ${ }^{\mathrm{a}, \mathrm{b}}$, Stefan M. Schmalholz ${ }^{\mathrm{a}}$ \\ ${ }^{a}$ Institute of Earth Sciences, University of Lausanne, 1015 Lausanne, Switzerland \\ ${ }^{b}$ Univ Rennes, CNRS, Géosciences Rennes - UMR 6118, F-35000 Rennes, France
}

\begin{abstract}
The generation of ductile shear zones is essential for the formation of tectonic plate boundaries, such as subduction or strike-slip zones. However, the primary mechanism of ductile strain localization is still contentious. We study here the spontaneous generation of ductile shear zones by thermal softening using thermo-mechanical numerical simulations for linear and power-law viscous flow in one-dimension (1D), 2D and 3D. All models are velocity-driven. The 1D model exhibits bulk simple shear whereas the 2D and 3D models exhibit bulk pure shear. The initial conditions include a small temperature perturbation in otherwise homogeneous material. We use a series of 1D simulations to determine a new analytical formula which predicts the temperature evolution inside the shear zone. This temperature prediction requires knowledge of only the boundary velocity, flow law and thermal parameters, but no a priori information about the shear zone itself, such as thickness, stress and strain rate. The prediction is valid for $1 \mathrm{D}, 2 \mathrm{D}$ and $3 \mathrm{D}$ shear zones in bulk pure and simple shear. The results show that shear heating dominates over conductive cooling if the relative temperature increase is $>50{ }^{\circ} \mathrm{C}$.
\end{abstract}

\footnotetext{
*corresponding author (daniel.kiss@unil.ch)
} 
The temperature variation induced by the shear zone is nearly one order of magnitude wider than the corresponding finite strain variation so that no significant temperature variation occurs between shear zone and wall rock. Applying typical flow laws for lithospheric rocks shows that shear zone generation by thermal softening occurs for typical plate tectonic velocities of few $\mathrm{cm} \cdot \mathrm{yr}^{-1}$ or strain rates between $10^{-16}$ and $10^{-14} \mathrm{~s}^{-1}$. Shear stresses larger than $200 \mathrm{MPa}$ can already cause strain localization. The results indicate that thermal softening is a feasible mechanism for spontaneous ductile shear zone generation in the lithosphere and may be one of the primary mechanisms of lithospheric strain localization.

Keywords: Ductile shear zone, thermal softening, strain localization, shear heating, localization criterion, subduction initiation

\section{Introduction}

The spontaneous generation of shear zones in ductile rocks is fundamental 3 for the formation of tectonic plate boundaries, such as subduction and strike slip 4 zones, or the generation of tectonic nappes during orogenic wedge formation.

tal shear zone parameters, such as thickness, shear stress and strain rate, are not a priori prescribed by the natural or model configuration. We refer to ductile deformation when the deformation behaviour is described mathematically by a relation between stress and strain rate, such as by flow laws for diffusion, dislocation or Peierls creep (i.e. low temperature plasticity). The conversion of dissipative work into heat, the related local temperature increase and the associated decrease of temperature dependent rock viscosities has frequently been suggested as a cause of spontaneous strain localization and shear zone formation in the litho- 
sphere (Yuen et al., 1978; Regenauer-Lieb and Yuen, 1998; Leloup et al., 1999; Kaus and Podladchikov, 2006; Takeuchi and Fialko, 2012; Thielmann and Kaus, 2012; Duretz et al., 2015; Jaquet et al., 2015; Moore and Parsons, 2015). We refer here to this thermally controlled strain localization mechanism as thermal softening. Despite its fundamental thermo-mechanical feasibility (Hersey, 1936; Brinkman, 1951; Gruntfest, 1963), shear heating and thermal softening is still contentious as important softening mechanism causing strain localization in ductile rock (Regenauer-Lieb et al., 2001; Platt and Behr, 2011; Bercovici and Ricard, 2012; Ghazian and Buiter, 2013; Gueydan et al., 2014; Platt, 2015). This is, for example, different from physics-based models of friction in rock where essentially all potential processes causing significant friction weakening are considered to be related to shear heating, such as "flash heating", thermal pressurization or temperature controlled chemical/phase changes, including melting and formation of pseudotachylites (Sibson, 1975; Fialko and Khazan, 2005; Brown and Fialko, 2012; Aharonov and Scholz, 2018). For ductile strain localization, proposed alternative mechanisms not related to shear heating are, for example, grain size reduction (Bercovici and Ricard, 2012; Platt, 2015), reaction-weakening caused by infiltration of fluids along precursor brittle faults (White and Knipe, 1978; Mancktelow and Pennacchioni, 2005) or fabric development in rock with significant mechanical heterogeneities (Montési, 2013). Out of the different mechanisms proposed for ductile strain localization, shear heating and thermal softening (1) must occur in nature since dissipative deformation generates heat and rock viscosity is temperature dependent and (2) requires the least assumptions since no knowledge concerning grain size reduction and growth, fluid flow, reaction kinetics or mechanical heterogeneities required for fabric evolution is needed. Hence, ther- 
mal softening as mechanism itself is actually not contentious, but whether thermal softening alone can be significant enough to generate shear zones in ductile rock under natural conditions is debated, as well as its relative importance compared to other localization mechanisms.

A long-lived argument against the significance of thermal softening during ductile deformation in the lithosphere is that many natural shear zones with thickness ranging from hundreds of meters to several kilometers do not indicate a sharp change in temperature between the little-deformed wall rock and the highlydeformed shear zone. This argument persists, despite the fact that several thermomechanical studies have shown that even if a shear zone is caused by thermal softening, there are only small temperature gradients between the shear zone and the wall rock (e.g., Yuen et al. 1978; Takeuchi and Fialko 2012; Schmalholz and Duretz 2015; Mako and Caddick 2018). Another argument against the importance of thermal softening is that the required shear stresses or the required strain rates are too large for typical lithospheric deformation conditions (e.g. Platt, 2015).

To test the validity of the above arguments against thermal softening and to quantify thermal softening, we use a thermo-mechanical numerical model of ductile rock deformation based on the conservation equations of continuum mechanics and apply constitutive equations for ductile creep. We perform a scaling analysis with results of a one-dimensional (1D) model for which simple shearing is controlled by a boundary velocity and strain localization can be triggered by a temperature, hence viscosity, perturbation in the model center. We apply a temperature perturbation because such perturbation diffuses away if shear heating is not efficient. In contrast, a viscosity perturbation (i.e. perturbation of material properties) would remain even if shear heating is insufficient and would, hence, always 
generate a shear zone in the $1 \mathrm{D}$ model, with a thickness of the initial viscosity perturbation. The model configuration is based on the model of Yuen et al. (1978) because for this configuration "No a priori assumption about slip-zone width or shear-stress magnitude is necessary; the thermal-mechanical structure of the slip zone evolves in time and all its characteristics are self consistently determined" (Yuen et al., 1978). These model features are essential to study spontaneous generation of shear zones in homogeneous material. Yuen et al. (1978) considered linear viscous flow laws only whereas we also consider power-law viscous flow laws to apply our results to lithospheric dislocation creep flow laws which exhibit power-law stress exponents typically between 2 and 4 (Table 1).

The aims of our study are to (1) quantify the temperature increase required for spontaneous shear zone generation, (2) quantify the relation between the width of the temperature variation across the shear zone and the width of the corresponding finite strain variation, (3) quantify stresses, velocities and strain rates required for shear zone generation, (4) derive an analytical formula which predicts the temperature inside a shear zone without a priori knowledge of the thickness, stress and strain rate of the shear zone, (5) compare the 1D model for bulk simple shear with 2D and 3D models for bulk pure shear and (6) evaluate the importance of thermal softening for ductile strain localization in the lithosphere.

\section{Mathematical and numerical model}

\subsection{Governing system of equations}

We assume incompressible viscous deformation in the absence of gravity and inertial forces. The governing system of equations is 


$$
\begin{aligned}
-\frac{\partial v_{i}}{\partial x_{i}} & =0 \\
-\delta_{i j} \frac{\partial P}{\partial x_{i}}+\frac{\partial \tau_{i j}}{\partial x_{j}} & =0 \\
\rho c_{p} \frac{\partial T}{\partial t}-\frac{\partial}{\partial x_{i}}\left(\lambda \frac{\partial T}{\partial x_{i}}\right)-\tau_{i j} \dot{\epsilon}_{i j} & =0 \\
\tau_{i j} & =2 \mu_{\mathrm{eff}} \dot{\epsilon}_{i j} \\
\mu_{\mathrm{eff}}\left(\dot{\epsilon}_{\mathrm{II}}, T\right) & =A^{-\frac{1}{n}} \dot{\epsilon}_{\mathrm{II}}^{\frac{1}{n}-1} \exp \left(\frac{Q}{n R T}\right)
\end{aligned}
$$

where equation (1), (2) and (3) are the equations for conservation of mass, linear momentum and energy, respectively, equation (4) is the creep flow law (constitutive equation) and equation (5) states the effective viscosity. The indices $i$ and $j$ correspond to coordinate axes 1, 2 and 3 and repeated indices imply summation. In equation (3) we assume that all dissipative work is converted to heat (so-called Taylor-Quinney coefficient is 1.0) since we do not consider grain size reduction which consumes typically only a minor fraction of the dissipative work (Herwegh et al., 2014; Thielmann et al., 2015). $x_{i}$ are the components of the spatial coordinates $[\mathrm{m}], t$ is the time $[\mathrm{s}], v_{i}$ are components of the velocity vector $\left[\mathrm{m} . \mathrm{s}^{-1}\right], \delta_{i j}$ is the Kronecker delta, $\tau_{i j}$ are components of the deviatoric stress tensor [Pa], $\rho$ is density $\left[\mathrm{kg} . \mathrm{m}^{-3}\right], c_{p}$ is heat capacity at constant pressure $\left[\mathrm{J} . \mathrm{K}^{-1}\right], T$ is temperature $[\mathrm{K}], \lambda$ is thermal conductivity $\left[\mathrm{W} . \mathrm{K}^{-1} \cdot \mathrm{m}^{-1}\right], \mu_{\mathrm{eff}}$ is effective viscosity [Pa.s], $\dot{\epsilon}_{i j}$ are components of the deviatoric strain rate tensor $\left[\mathrm{s}^{-1}\right], \dot{\epsilon}_{\mathrm{II}}$ is the square root of the second invariant of the strain rate tensor $\left[\mathrm{s}^{-1}\right], n$ is the power law exponent [ ], $A$ is the pre-exponential factor $\left[\mathrm{Pa}^{n} \cdot \mathrm{s}^{-1}\right], \mathrm{Q}$ is activation energy $\left[\mathrm{J} \cdot \mathrm{mol}^{-1}\right]$ and $R$ is the universal gas constant $\left[\mathrm{J} \cdot \mathrm{mol}^{-1} \cdot \mathrm{K}^{-1}\right]$. 
Initial and boundary conditions are

$$
\begin{aligned}
& T\left(\sqrt{x_{i} x_{i}}>r, t=0\right)=T_{0} \text { and } T\left(\sqrt{x_{i} x_{i}} \leq r, t=0\right)=T_{0}+\Delta T_{0} \\
& q_{i}\left(x_{i}=\left[0 \text { or } L_{i}\right], t\right)=0 \\
& v_{i}\left(x_{j}=0, t\right)=0 \text { and } v_{i}\left(x_{j}=L_{j}, t\right)=\Delta v_{i}
\end{aligned}
$$

where $T_{0}$ is initial temperature [K], $\Delta T_{0}$ is the value of the intial temperature perturbation $[\mathrm{K}], q_{i}$ are components of the heat flux vector $\left[\mathrm{W} \cdot \mathrm{m}^{-2}\right], L_{i}$ is the total size of the model domain $[\mathrm{m}]$ in the different spatial directions and $\Delta v_{i}$ is the farfield velocity difference $\left[\mathrm{m} \cdot \mathrm{s}^{-1}\right]$ in the different spatial directions. The material parameters are homogenous and the initial temperature is constant except a small temperature perturbation, $\Delta T_{0}$, in a region around the model centre, $x_{i}=0$, whose size is specified with radius $r$ (eq. 6, Fig.1). This thermal perturbation mimics any kind of small variation of strength or thermal properties which are always present in natural rocks. The model is thermally insulated (eq. 7). For simple shear type deformation the model is kinematically driven by constant far-field boundary velocities (eq. 8). For pure shear type deformation in 2D and 3D only velocities normal to the boundaries are defined (i.e. $i=j$ for eq. 8), otherwise free slip boundary conditions are used, so shear stresses are zero at the boundaries.

\subsection{Numerical method}

The system of non-linear equations (Eq. 1-5) is discretized on a regular Cartesian staggered grid. The problem is solved by a pseudo-transient iteration or relaxation scheme (Versteeg and Malalasekra, 2007; Duretz et al., 2019). The thermo-mechanical equations are recasted in the following form: 


$$
\begin{aligned}
\frac{\mathrm{d} P}{\mathrm{~d} \omega} & =\frac{\partial v_{i}}{\partial x_{i}}, \\
\frac{\mathrm{d} v_{i}}{\mathrm{~d} \omega} & =\frac{\partial \tau_{i j}}{\partial x_{j}}-\frac{\partial P}{\partial x_{i}}, \\
\frac{\mathrm{d} T}{\mathrm{~d} \omega} & =\rho c_{p} \frac{\partial T}{\partial t}-\frac{\partial}{\partial x_{i}}\left(\lambda \frac{\partial T}{\partial x_{i}}\right)-\tau_{i j} \dot{\epsilon}_{i j} .
\end{aligned}
$$

where $\frac{\mathrm{d} P}{\mathrm{~d} \omega}, \frac{\mathrm{d} v_{i}}{\mathrm{~d} \omega}$ and $\frac{\mathrm{d} T}{\mathrm{~d} \omega}$ are derivatives of pressure, velocities and temperature with respect to pseudo time $\omega$. We consider here incompressible deformation in the absence of inertia which corresponds to the equations when the pseudo-time derivatives have vanished. These pseudo-transient derivatives allow for an iterative solve of the non-linear system of equations. At each physical time step, an explicit integration of the non-linear equation is carried out until the pseudo time derivatives vanish and steady state is achieved. A fully implicit solution of the heat equation is obtained by evaluating the heat flux and shear heating term at each pseudotransient iteration. The evaluation of temperature and strain rate dependent viscosity is embedded within the pseudo transient iteration cycle. The pseudo transient algorithm is easily extendable to $2 \mathrm{D}$ and $3 \mathrm{D}$ configurations and is also well suited for vectorized parallel computations (see e.g. Omlin, 2016).

\section{3. $1 D, 2 D$ and $3 D$ model configurations}

The 1D model domain extends orthogonally across the shear zone and velocities are orthogonal to the model domain. The 1D model is driven by a velocity difference at the two model boundaries which imposes a bulk simple shear deformation (Fig. 1a). To test whether results of the 1D model are applicable to $2 \mathrm{D}$ and $3 \mathrm{D}$ shear zones, we perform also 2D and 3D numerical simulations for bulk pure shear. For the 3D model shortening occurs in one horizontal direction 
and extension in the vertical direction while the bulk extension in the second horizontal dimension is zero (Fig. 1c). The initial temperature perturbation has the shape of a quarter circle in the 2D model (Fig. 1b) and one eight of a sphere in the 3D model (Fig. 1c). To compare the 2D and 3D results with the 1D results we record the temperature and shear velocities along a profile line, with coordinates $x^{\prime}$, which is orthogonal to the $2 \mathrm{D}$ and $3 \mathrm{D}$ shear zones. These results are directly comparable with the results of the corresponding 1D model (Fig. 1).

\section{Fundamental features of 1D shear zone evolution}

There are two end-member solutions of the numerical model: (1) The velocity field converges to homogeneous simple shear in the entire model domain, there is no strain localization and the temperature increases homogeneously in the model domain due to bulk shear heating. (2) The temperature increases locally in the model center, which causes strain localization and the generation of a shear zone that is much thinner than the model domain. We show in the following fundamental features of solution (2) for representative simulations.

For simulations with linear viscosity the temperature increases in the shear zone during a transient stage and then reaches a constant temperature (Fig. 2a), in agreement with Fleitout and Froidevaux (1980). This temperature is independent on the initial temperature perturbation and model width (Fig. 2a). For simulations with power-law viscous flow laws the temperature also increases in the shear zone during a transient stage and then reaches a quasi-constant temperature (Fig. $2 b$ ). In contrast to the linear viscous model the temperature in the shear zone does not reach a strictly-constant value, but the temperature is slightly increasing with ongoing deformation, referred to here as quasi-constant (Fig. 2b). This 
quasi-constant temperature is also independent on the initial temperature perturbation and the model width (Fig. 2b). For such quasi-constant temperature in the shear zone center, shear heating must be locally balanced by thermal conduction (Eq. 3). Fleitout and Froidevaux (1980) showed that constant boundary velocities guarantee that this balance is always reached. Hence, velocity-driven shearing of a dominantly viscous medium does not lead to a thermal runaway for which temperatures would increase exponentially, in an unbounded way.

The presented model results correspond to simulations with significant shear localization in the model center and show that a modest temperature rise of 100 ${ }^{\circ} \mathrm{C}$ can result in shear localization due to thermal softening (Fig. 2a and b).

The shear stress is spatially constant in the 1D model at each instant of time, it is largest at the onset of deformation and decreases with time due to progressive temperature increase due to shear heating (Fig. 2c). When the maximal temperature reaches a quasi-constant value then also the stress reaches a quasi-constant value.

The characteristic width of the temperature variation across the shear zone, referred to here as thermal thickness, is not prescribed a priori but controlled by the thermo-mechanical process (Duretz et al., 2014, 2015). After the maximal temperature has reached its (quasi-)constant value, the thermal thickness is increasing proportional with the square root of time due to thermal conduction (Fig. 3a). In the following, we distinguish between the thermal thickness and the finite strain thickness that is determined by the width of the finite strain profile (Fig. 4a). The thermal thickness is defined as the width of the temperature profile at this temperature, which is half between the maximal temperature in the shear zone center and the minimal ambient temperature far away from the shear zone (Fig. 3a). During 
the transient stage of temperature increase the thermal thickness is typically decreasing (Fig. 3b). The thermal thickness evolution is essentially unaffected by the initial temperature perturbation and model size, similar to the evolution of the maximum temperature (Fig. 3b).

The temperature profile is significantly wider than the corresponding finite strain $(\gamma)$ profile across the shear zone (Fig. 4a), which agrees with results of Takeuchi and Fialko (2012) for strike slip zones and of Schmalholz and Duretz (2015) for thrust-type shear zones. $\gamma$ is calculated by time integration of the shear strain rates. The finite strain thickness is measured in the same way as the thermal thickness, that is, the width of the $\gamma$-profile at the value of $\gamma$ half between the maximum value and the far-field value at the model boundary (Fig. 4a). The ratio of thermal to finite strain thickness increases during the transient phase of temperature increase. Once the temperature has reached its (quasi-)constant value this ratio converges towards a constant value. This shows that the finite strain and thermal thickness are linked, both are controlled by thermal conduction. After the transient phase, the thermal thickness is nearly one order of magnitude (factor 6 to 8) larger than the finite strain thickness (Fig. 4b). The example presented in figure 4a shows that a significant decrease of $\gamma$ from ca. 17, in the shear zone center, to 1 is associated with only a minor temperature decrease from ca. $800^{\circ} \mathrm{C}$ to $760^{\circ} \mathrm{C}$ (i.e. only a $20 \%$ decrease).

\section{Predictive scaling relationships and localization criterion}

We performed a series of 1D numerical simulations with a geologically applicable range for all independent model parameters: $\Delta v, A, \rho, c_{\mathrm{p}}, \lambda, T_{0}, n$ and $Q$. For each parameter we used several representative values which were evenly dis- 
tributed within the chosen range (e.g.: $\mathrm{n}=\{1,2,3,5,6\}$ ). To test the usefulness of several different sets of independent scales, we performed these simulations using the dimensional form of equations (4), (5) and (9). We run 1D simulations with all parameter combinations and recorded characteristic parameter values (e.g.: $T_{\max }$, $\left.\mu_{\text {min }}\right)$ in regular intervals during shear zone evolution. We recorded data from more than 45’000 simulation stages (i.e. at specific times) from ca. 2’000 simulations.

\subsection{Thermal thickness of shear zones}

All simulations show that shear zones are widening proportional to the square root of time (Fig. 3) and that widening is controlled by heat conduction. Two fundamental types of conductive heat transfer between shear zone and surrounding region can be distinguished: (1) If there is no significant shear heating, then the initially higher temperature in the model center is decreasing with respect to the far-field temperature during shearing and the temperature evolution in the model can be approximated with an analytical solution for Gaussian cooling of an initial Dirac delta temperature profile (Fig. 5a). The spatial and temporal evolution of temperature can then be described by the equation:

$$
\Delta T(x, t)=\frac{1}{\sqrt{4 \pi \kappa t}} \exp \left(-\frac{x^{2}}{4 \kappa t}\right)
$$

If the maximum temperature is in the model center, at $x=0$, then the half width of the temperature profile is given by the value of $x$ for which $\Delta T(x, t)=$ $0.5 \Delta T_{\max }(t)$ : 


$$
\begin{array}{r}
\frac{\Delta T_{\max }(t)}{2}=\frac{1}{2 \sqrt{4 \pi \kappa t}}=\frac{1}{\sqrt{4 \pi \kappa t}} \exp \left(-\frac{x^{2}}{4 \kappa t}\right) \rightarrow \\
0.5=\exp \left(-\frac{x^{2}}{4 \kappa t}\right) \rightarrow x=\sqrt{-4 \ln (0.5) \kappa t} \approx 1.67 \sqrt{\kappa t}
\end{array}
$$

The corresponding full width of the Gaussian temperature profile, $W_{\mathrm{G}}$ is then:

$$
W_{\mathrm{G}} \approx 3.34 \sqrt{\kappa t} \Longleftrightarrow W_{\mathrm{G}} / \sqrt{\kappa t} \approx 3.34
$$

(2) If there is significant shear heating, then the temperature in the model center reaches a (quasi-)constant value after a transient period (Fig. $2 \mathrm{a}$ and b). The temperature evolution in model can then be described with a half space heating model in which the temperature is kept constant at one side, representing the shear zone center, and the far-field temperature is the initial temperature at the model boundary. The analytical solution for the temperature evolution for such scenario quantifies the heating of a half-space, representing the region adjacent to the shear zone and is given by an error function solution (Fig. 5a):

$$
\Delta T(x, t)=\Delta T_{\max } \operatorname{erfc}\left(\frac{x}{2 \sqrt{\kappa t}}\right)
$$

If the maximum temperature is in the model center, at $x=0$, then the half width of the temperature profile is given by the value of $x$ for which $\Delta T(x, t)=0.5 \Delta T_{\max }(t)$ :

$$
\frac{\Delta T_{\max }}{2}=\Delta T_{\max } \operatorname{erfc}\left(\frac{x}{2 \sqrt{\kappa t}}\right) \rightarrow 0.5=\operatorname{erfc}\left(\frac{x}{2 \sqrt{\kappa t}}\right)
$$

Using the approximation $\operatorname{erfc}(0.48) \approx 0.5$ yields:

$$
0.48 \approx \frac{x}{2 \sqrt{\kappa t}} \rightarrow x \approx 0.96 \sqrt{\kappa t}
$$

The corresponding full width of such temperature profile, $W_{\mathrm{E}}$, is then:

$$
W_{\mathrm{E}} \approx 1.92 \sqrt{\kappa t} \Longleftrightarrow W_{\mathrm{E}} / \sqrt{\kappa t} \approx 1.92
$$


If thermal evolution during shearing is dominated by conductive cooling, then the width of the temperature across the shear zone will grow according to $W_{\mathrm{G}}$, and according to $W_{\mathrm{E}}$ if thermal evolution is dominated by shear heating. We plotted the dimensionless widths, scaled by $\sqrt{\kappa t}$, of the numerically calculated temperature profiles versus the maximal temperature difference (i.e. maximum temperature in the shear zone center minus initial temperature, $\Delta \mathrm{T}$ ) recorded in the numerical simulations (Fig. 5b). For insignificant shear heating, $\Delta T<$ ca. 20 ${ }^{\circ} \mathrm{C}$, the temperature profile is widening according to $W_{\mathrm{G}}$ (Fig. 5b). For significant shear heating, $\Delta T>\mathrm{ca} .100^{\circ} \mathrm{C}$, the temperature profile is widening according to $W_{\mathrm{E}}$ (Fig. 5b). Between 20 and $100^{\circ} \mathrm{C}$ for $\Delta T$ there is a transition zone where the thicknesses are in between $W_{\mathrm{E}}$ and $W_{\mathrm{G}}$. The boundary between the two heat transfer domains occurs at $\Delta T \approx 40^{\circ} \mathrm{C}$. The results, hence, indicate that a temperature increase of at least $40{ }^{\circ} \mathrm{C}$ in the shear zone is required so that shear heating dominates the heat transfer across the shear zone.

\subsection{Maximum temperature of shear zones}

After a transient phase the temperature in the shear zone is (quasi-)constant. For such quasi steady state, heat production and conduction are essentially balanced in the shear zone, that is:

$$
\left.0 \approx \rho c_{p} \frac{\partial T}{\partial t}\right|_{x=0}=\left.\lambda \frac{\partial^{2} T}{\partial x^{2}}\right|_{x=0}+\left.\mu\left(\frac{\partial v}{\partial x}\right)^{2}\right|_{x=0}
$$

For this quasi steady state, we want to determine a scaling relationship between the term representing diffusion (with $\lambda$ in Eqn. 18) and the term representing shear heating (with $\mu$ ). Such relationship can be of the form:

$$
\lambda T_{\mathrm{c}} \approx a \mu_{\mathrm{c}} v_{\mathrm{c}}^{2}
$$


where the subscripts $\mathrm{c}$ indicate a characteristic value of the corresponding parameter, and $a$ is a proportionality constant. The characteristic length scale has been dropped because it has the same power in both terms for diffusion and heat production (right side of Eqn. 18). Because the quasi steady state occurs only in the shear zone center, it is reasonable to chose characteristic values that are representative for this location. There are several formally correct and reasonable choices for the characteristic values, but after testing the scaling relationship (19) with the numerical results, we found that $T_{\mathrm{c}}=R T_{\max }^{2} / Q, v_{\mathrm{c}}=\Delta v$ and $\mu_{\mathrm{c}}=\mu_{\min }$ provides the best fit. $T_{\max }$ and $\mu_{\min }$ are always the maximal temperature and minimum viscosity, respectively, in the shear zone center. Based on equation (19) and these characteristic values, $T_{\max }$ can be predicted with:

$$
T_{\max } \approx \frac{\Delta v}{\mathrm{e}} \sqrt{\frac{\mu_{\min } Q}{\lambda R}}
$$

where $\mathrm{e} \approx 2.72$ is the Euler number, and $\mathrm{e}^{-1}$ is the proportionality constant $a$ (Fig. 6a). All parameters in this formula correspond to a specific time during shear zone evolution. Equation 20 is useful in applications where a shear zone viscosity ( $\mu_{\min }$ as a function of $T_{\max }$ and $\dot{\epsilon}_{\mathrm{II}_{\max }}$ or $\tau_{\mathrm{II}}$ ) can be constrained, for example, for rock deformation experiments. For most natural shear zones viscosities cannot be easily constrained. This is because, for example, for power-law viscous flow knowledge of the strain rate is required to determine the effective viscosity. We approximate the strain rate by the ratio of $\Delta v / \sqrt{\kappa t}$ assuming that $\sqrt{\kappa t}$ provides a representative value for the shear zone thickness. Using then the dataset from all the 1D simulations we determine a formula to fit the shear zone viscosity:

$$
\mu_{\min } \approx 1.28 \frac{\mathrm{e}^{2} \lambda Q}{\Delta v^{2} n^{2} R}\left[\ln \left(\frac{\Delta v^{2} n R}{\lambda Q} A^{-\frac{1}{n}}\left\{\frac{\Delta v}{\sqrt{\kappa t}}\right\}^{\frac{1}{n}-1}\right)+1.1\right]^{-2}
$$


For $n=1$ the term with the approximate strain rate disappears. If we substitute the approximation of the shear zone viscosity in equation (20) we get:

$$
T_{\max } \approx-1.13 \frac{Q}{n R}\left[\ln \left(\frac{\Delta v^{2} n R}{\lambda Q} A^{-\frac{1}{n}}\left\{\frac{\Delta v}{\sqrt{\kappa t}}\right\}^{\frac{1}{n}-1}\right)+1.1\right]^{-1}
$$

Crosschecking with the numerical results provides the minus sign for taking the square root of $\mu_{\min }$ in Eqn. 20. Equation 22 predicts the maximum temperature in all numerically simulated shear zones with a maximal error of $<50{ }^{\circ} \mathrm{C}$ and with a root mean square error of only $20^{\circ} \mathrm{C}$ (Fig. 6b). The prediction of $T_{\max }$ using equation (22) does not require any a priori knowledge of the shear zone thickness, the stress, the strain rate and the effective viscosity in the shear zone. The great advantage of equation (22) is, hence, that $T_{\max }$ inside a shear zone can be estimated exclusively with flow law parameters $(n, A$ and $Q)$, thermal parameters ( $\lambda$ and $\left.c_{p}\right)$, the density $(\rho)$, the applied boundary velocity difference $(\Delta v)$ and the duration $(t)$ of shearing.

\subsection{Localization criteria}

A possible criterion for shear localization is that shear heating must dominate the heat transfer between shear zone and the surroundings. Based on the results discussed in the previous section we suggest $T_{\max }-T_{0}>50{ }^{\circ} \mathrm{C}$ as localization criterion. An alternative criterion can be derived by separating the variables and the constant $e$ in equation (20) and squaring both sides, which yields:

$$
\frac{\Delta v^{2} \mu_{\min } Q}{\lambda R T_{\max }^{2}} \approx \mathrm{e}^{2}
$$

If the maximum temperature is replaced by the smaller initial temperature, $T_{0}$, and the minimum viscosity by the larger initial viscosity, $\mu_{0}$, then a modified criterion 
for shear localization is:

$$
B r_{1}=\frac{\Delta v^{2} \mu_{0} Q}{\lambda R T_{0}^{2}}>\mathrm{e}^{2}
$$

The dimensionless number on the left hand side is a particular version of the Brinkman number $\left(B r_{1}\right)$. Several authors suggested different versions of the Brinkman number as criterion of shear localization, based on scaling analyses (e.g. Brinkman 1951; Gruntfest 1963; Yuen et al. 1978; Brun and Cobbold 1980). Another typical version of the Brinkman number $\left(B r_{2}\right)$ is $B r_{1}$ divided by the Arrhenius exponent $\left(Q / R T_{0}\right)$. The corresponding localization criterion is then:

$$
B r_{2}=\frac{\Delta v^{2} \mu_{0}}{\lambda T_{0}}>1
$$

We plotted the values of both $B r_{1}$ and $B r_{2}$ versus the viscosity decrease in the shear zone center $\left(\mu_{\min } / \mu_{0}\right)$ for all simulations. Both numbers are proportional to the viscosity decrease (Fig. 6c), hence they are useful criteria for strain localization. We prefer using the criterion $T_{\max }-T_{0}>50{ }^{\circ} \mathrm{C}$ due to its simplicity, or the criterion based on $B r_{1}$ because it has been directly derived from the analytical formula (eq. 20).

\section{Comparison of $1 \mathrm{D}, 2 \mathrm{D}$ and $3 \mathrm{D}$ shear zones}

Equations 20 and 22 for predicting the temperature in the shear zone are based on a 1D model, which is driven by far-field simple shear. We apply this prediction to shear zones that develop in 2D and 3D models, which are driven by far-field pure shear, in order to test the general applicability of the temperature prediction (Fig. 7). The rate of temperature increase in the shear zone is the largest for the 1D model and the smallest for the 3D model. This is because in the 1D model the initial thermal perturbation is at the position of the future shear zone whereas in 
the 2D (Fig. 7d to f) and 3D (Fig. 7a to c) models the initial thermal perturbation is present only in a fraction of the future shear zones. Also, the background temperature increase due to bulk shear heating of the model domain is the largest in the 3D and the smallest in the 1D model (Fig. $7 \mathrm{~g}$ to i). Nevertheless, equation 22 (associated with the 1D results) accurately predicts the temperature inside the $2 \mathrm{D}$ and 3D shear zones after the transient stage of temperature increase. The results also confirm that the initial temperature perturbation applied in the $1 \mathrm{D}$ model has no impact on the maximum temperature in the shear zone because the temperature of the $2 \mathrm{D}$ and $3 \mathrm{D}$ shear zones are unaffected by the initial thermal perturbation. A comparison of profiles of the velocities parallel to the 1D, 2D and 3D shear zones shows that the thickness of the shear zones are essentially identical. Therefore, 1D, 2D and 3D shear zones caused by thermal softening under both far-field pure and simple shear exhibit the same thermo-mechanical characteristics.

\section{Application to dislocation creep flow laws}

We apply equation 22 to predict the maximum temperature in shear zones using typical flow laws for rock-forming minerals relevant to the lithosphere. Equation (22) depends on the duration of deformation. The typical, observed time scale of deformation varies as a function of shear velocity. To make the results for different velocities comparable we assume a characteristic shear strain of 20 , which is the ratio of displacement and shear zone thickness $\left(W_{\gamma}\right)$. As a first order estimate we use one tenth (Fig 4b) of the characteristic thermal width $W_{T}=2 \sqrt{\kappa t}$ (Fig. 5b) as a shear zone width. With these relationships we can determine a representative characteristic time of the deformation to reach a shear strain of 20 :

$$
20=\gamma_{\mathrm{c}}=\frac{t_{\mathrm{c}} \Delta v}{0.2 \sqrt{\kappa t_{\mathrm{c}}}} \rightarrow t_{\mathrm{c}}=\left(0.2 \frac{\gamma_{\mathrm{c}} \sqrt{\kappa}}{\Delta v}\right)^{2}
$$


which yields $t_{\mathrm{c}} \approx 5 \mathrm{Ma}$ for a velocity of $\approx 1 \mathrm{~cm} \cdot \mathrm{yr}^{-1}$.

For typical plate tectonic velocities in the order of few centimeters per year, the flow laws for wet and dry olivine, and dry plagioclase are associated with maximum temperatures between 500 and $700{ }^{\circ} \mathrm{C}$ (Fig. 8). Such temperatures correlate well with typical temperatures of highly sheared basement nappes outcropping in orogens such as the Alps. Typical metamorphic peak temperature ranges between 500 and $650{ }^{\circ} \mathrm{C}$ (Keller et al., 2005; Manzotti et al., 2018) and reach up to 800 ${ }^{\circ} \mathrm{C}$ in the Lepontine dome (Nagel, 2008). Takeuchi and Fialko (2012) provided a thorough study of the temperature anomalies around the San Andreas strike-slip fault. They used heat flow and surface deformation measurements to constrain their models. They conclude that a temperature increase of 160 to $375^{\circ} \mathrm{C}$, dependent on rheology, is expected at $20 \mathrm{~km}$ depth for a $4 \mathrm{~cm} \cdot \mathrm{yr}^{-1}$ long term average velocity difference. These values are in a good agreement with our prediction for dry anorthite and olivine and wet olivine flow laws. Flow laws for wet quartzite and Westerly granite provide maximal temperatures $<300{ }^{\circ} \mathrm{C}$ in the same velocity range (Fig. 8).

A recent study of Chu et al. (2017) provides well constrained information about the duration of deformation and maximal temperature of eclogite shear zones of the Taconic orogenic belt (New England). The eclogite bodies are hosted in feldspar rich felsic paragneiss. The authors conclude that the $P-T$ history of the shear zones can be best explained by shear heating. Using the known displacement, related to the known deformation time, the shear velocities can be constrained to be between $25-70 \mathrm{~cm} \cdot \mathrm{yr}^{-1}$. For the inferred velocity range the applicable flow law for dry anorthite yields a good fit (Fig. 8).

Rocks that are commonly considered to result from significant shear heating 
are pseudotachylites. They are often associated to earthquakes, having typically slip velocities on the order of a m.s ${ }^{-1}$ (Bizzarri, 2012). Such fast deformation processes are commonly considered to be dominated by frictional deformation and, hence, frictional heating. However, recent progress in understanding of the physics of friction suggests viscous creep on grain contacts and asperities as the mechanism for velocity weakening of the friction coefficient, reported at high shear-velocity $\left(\approx 1 \mathrm{~m} \cdot \mathrm{s}^{-1}\right)$ rock deformation experiments for various rock types (Aharonov and Scholz, 2018). Moreover, a recent experimental study of high shear-velocity $\left(\approx 1 \mathrm{~m} \cdot \mathrm{s}^{-1}\right)$ deformation of calcite reports that such fast shear deformation is characterized by an initial frictional deformation followed by (quasi) steady-state viscous creep (Pozzi et al., 2018). In these experiments most of the strain is generated by (quasi) steady-state viscous creep. Since the (quasi) steady-state temperature developing in our models is path independent (Fig. 2), we can apply our viscous model result to estimate the temperatures in such small-scale and high-velocity shear zones regardless of which deformation mechanism dominates initially. To test the model-based temperature estimations we consider natural pseudotachylites from Corsica (Andersen et al., 2008). The reported peak metamorphic temperature is at least $1750^{\circ} \mathrm{C}$. There are no reported constraints on shear velocities and, therefore, we apply peak slip velocities of 4 $\mathrm{m} . \mathrm{s}^{-1}$ (that is typical for seismic events with a displacement around $1 \mathrm{~m}$ ), as an upper limit (Bizzarri, 2012). To estimate a lower bound, we use the width of the main pseudotachylite vein $(W=1.23 \mathrm{~cm})$, the displacement $(d=1 \mathrm{~m}$, yielding $\gamma_{\mathrm{c}}=d / W \approx 80$ ) along it and the scaling relationship between characteristic width of shear zones and the duration of deformation (eq. 16). Reordering equation (16) yields $t=W^{2} /\left(1.92^{2} \kappa\right) \approx 41 \mathrm{~s}$ (assuming $\left.\kappa \approx 10^{-6} \mathrm{~m}^{2} \cdot \mathrm{s}^{-1}\right)$. Using 
this estimate of duration we can estimate the slip velocity $v=d / t \approx 0.02\left[\mathrm{~m} \cdot \mathrm{s}^{-1}\right]$. As such estimates have typically an order of magnitude uncertainty we take a five times lower value as a lower velocity bound (i.e. $4 \mathrm{~mm} . \mathrm{s}^{-1}$ ). Within this wide velocity range, the predicted temperatures for most flow laws agree with the reported peak temperature (Fig. 8). Clearly, there are many uncertainties and simplifications related to this temperature estimate, but this estimate nevertheless indicates that peak temperatures reported for the considered pseudotachylites potentially could have been generated in viscous shear zones for typical slip velocities, in the order of $1 \mathrm{~m} \cdot \mathrm{s}^{-1}$.

Whether shear heating causes shear localization depends on the initial temperature of the rock because localization will not occur if the ambient rock temperature at the onset of shearing is larger than the predicted maximum temperature. We consider typical lithospheric geotherms and temperatures for the upper crust between 200 and $400{ }^{\circ} \mathrm{C}$, for the lower crust between 400 and $600{ }^{\circ} \mathrm{C}$ and for the mantle lithosphere $>600{ }^{\circ} \mathrm{C}$. For typical plate tectonic velocities, we calculate the predicted maximum temperature for different initial temperatures representing the ambient temperature at the onset of deformation (Fig. 9a). The temperature difference, $\Delta T$, between predicted maximal temperature and initial, ambient, temperature indicates the intensity of shear heating and, hence, shear localization by thermal softening. Shear heating is significant for $\Delta T>50{ }^{\circ} \mathrm{C}$ since for such values of $\Delta T$ the heat transfer between shear zone and wall rock is dominated by shear heating (Fig. 5b). For plate tectonic velocities of a few $\mathrm{cm} \cdot \mathrm{yr}^{-1}$, shear heating is always important in all three lithospheric units (Fig. 9a). As expected, for the same velocity shear heating is always more intense in the upper and colder regions of the lithospheric units. For example, for a velocity difference 
of $3 \mathrm{~cm} \cdot \mathrm{yr}^{-1}$ the expected temperature increase in a lower crust made of ca. 400 ${ }^{\circ} \mathrm{C}$ hot anorthite is between 100 and $150{ }^{\circ} \mathrm{C}$ (Fig. 9a).

Shear heating is even more important if we consider a thinned thermally relaxed continental lithosphere, for example, at a passive continental margin. This is because the temperatures at the top of the lower crust and mantle lithosphere are colder than for a normal continental lithosphere (Fig. 9b).

We also analyze the initial stresses for configurations for which shear heating and strain localization is significant (Fig. 9c and d). We consider scenarios for which $\Delta T>50{ }^{\circ} \mathrm{C}$ and for which initial shear stresses, $\tau_{x y}$, are $<1 \mathrm{GPa}$ (Fig. $9 \mathrm{c}$ and $\mathrm{d}$ ). The initial shear stresses are the largest stresses during shear zone formation since stress magnitudes decrease during shear zone formation due to thermal softening (Fig. 2c). We assume a velocity difference of $3 \mathrm{~cm} \cdot \mathrm{yr}^{-1}$ and vary initial bulk strain rates by varying the 1D model size, $L$. For flow laws of wet anorthite shear heating is significant for ambient temperatures between 380 and $470^{\circ} \mathrm{C}$ and for strain rates, $\dot{\epsilon}$, between $10^{-16}$ and $10^{-13} \mathrm{~s}^{-1}$. For example, for typical tectonic strain rates $\dot{\epsilon}=10^{-15} \mathrm{~s}^{-1}$ shear localization by thermal softening is significant for shear stresses between 200 and $400 \mathrm{MPa}$ for ambient temperature between 420 and $470{ }^{\circ} \mathrm{C}$ (Fig. 9c). For dry olivine and for $\dot{\epsilon}=10^{-15} \mathrm{~s}^{-1}$ thermal softening is significant for shear stresses between 200 and 400 MPa for ambient temperature between 540 and $570{ }^{\circ} \mathrm{C}$ (Fig. 9d).

Our results indicate that the shortening of a tectonic plate, for example around a thinned passive continental margin, can likely generate significant shear heating and associated spontaneous shear zone generation by thermal softening. Such shear zone generation can take place in the ductile regime without reaching a brittle-plastic yield stress. Ductile strain localization by thermal softening could 
cause the generation of subduction zones, which is supported by numerical simulations (e.g. Thielmann and Kaus 2012).

\section{Discussion}

\subsection{Localization criterion and Brinkman number}

We already suggested the use of $T_{\max }-T_{0}>50^{\circ} \mathrm{C}$ or $B r_{1}>\mathrm{e}^{2}$ as localization criterion. Different versions of the Brinkman number (e.g. Brinkman 1951; Gruntfest 1963; Yuen et al. 1978; Brun and Cobbold 1980) have been proposed and are also known under different names, for example, Gruntfest number $(G r)$. Using the relations $\Delta v=\dot{\epsilon}_{0} L$ and $\tau_{0}=\mu_{0} \dot{\epsilon}_{0}$, several Brinkman numbers can be formulated:

$$
B r_{2}=\frac{\Delta v^{2} \mu_{0}}{\lambda T_{0}}=\frac{\Delta v^{2} \mu_{0}}{\lambda T_{0}} \frac{L^{2}}{L^{2}}=\frac{\dot{\epsilon}_{0}^{2} \mu_{0} L^{2}}{\lambda T_{0}}=\frac{\dot{\epsilon}_{0} \tau_{0} L^{2}}{\lambda T_{0}}=\frac{\tau_{0}^{2} L^{2}}{\mu_{0} \lambda T_{0}}=G r
$$

The right-most version with the square of the stress is often termed Gruntfest number, $G r$. All parameters with the subscript 0 are initial, bulk values before the occurrence of strain localization or shear zone formation. The parameter $L$ is the model size and not the thickness of the shear zone. The same exercises can be repeated by dividing equation (27) with the dimensionless Arrhenius term $Q / R T_{0}$, and it would result in several forms of $B r_{1}$ (equation 24). A particular localization criterion would be

$$
\frac{Q}{R T_{0}} \frac{L^{2} \dot{\epsilon}_{0} \tau_{0}}{\lambda T_{0}}>\mathrm{e}^{2}
$$

which is identical to the criterion of Karato (2008), if $\mathrm{e}^{2}$ on the right hand side is replaced by 1 . The different versions of the Brinkman number are useful for different deformation scenarios. For example, if the deformation is driven by 
an applied shear stress, then the version with the square of the stress, i.e. $G r$, is useful. If the thickness of the shear zone is a priori defined by the model or experimental configuration, then a version including $L$ is useful whereby $L$ then represents the pre-defined shear zone thickness. In general, for kinematically driven models, we prefer versions without any length scale $L$, because the model size does not affect the shear zone evolution (Fig. 2a and 2b).

Our results show the applicability of three different localization criteria. As example, we use $\mathrm{Br}_{2}>1$ (Fig. 6c). Applying a typical plate tectonic velocity of $3 \mathrm{~cm} . \mathrm{yr}^{-1}$, an effective viscosity of $2 \times 10^{23}$ Pa.s, a thermal conductivity of 3 W. $\mathrm{m}^{-1} \mathrm{~K}^{-1}$ and an ambient temperature of $500{ }^{\circ} \mathrm{C}(773 \mathrm{~K})$ yields $B r_{2} \approx 78$. Our results show that for this value of $\mathrm{Br}_{2}$ shear zone generation by thermal softening can occur (Fig. 6c). Using a typical tectonic strain rate of $10^{-15} \mathrm{~s}^{-1}$, and the applied effective viscosity of $2 \times 10^{23}$ Pa.s generates a shear stress of $400 \mathrm{MPa}$, which is a feasible flow stress for the upper and colder regions of the mantle lithosphere or the lower crust. Indeed, the spontaneous generation of km-scale shear zones by thermal softening was demonstrated in 2D thermo-mechanical simulations of lithospheric shortening for viscoelastoplastic rheology (Jaquet et al., 2017; Jaquet and Schmalholz, 2017).

Here, we do not consider viscoelastic effects. However, it was shown that elasticity can significantly impact thermally-induced strain localisation (RegenauerLieb and Yuen, 1998; Duretz et al., 2015; Jaquet et al., 2015) so that strain localization can be even more significant than predicted by our localization criteria.

\subsection{Shear zone thickness}

A ductile shear zone is commonly observable in the field, or experiment, by the significant variation of finite strain across the shear zone. The width of the varia- 
tion of finite strain across the shear zone is nearly one order of magnitude smaller than the corresponding width of the temperature variation (Fig. 4b). For significant shear heating the finite strain thickness, $W_{\gamma}$, is ca. $2 \sqrt{\kappa t} / 7$ (Figs. $4 \mathrm{~b}$ and $5 \mathrm{~b}$ ). We assume that the observable width of a shear zone is determined by values of finite strain $>1$. Based on Fig. 4a this observable thickness is approximately 2 to 3 times thicker than $W_{\gamma}$. Assuming a typical thermal diffusivity of $10^{-6} \mathrm{~m}^{2} \cdot \mathrm{s}^{-1}$ yields $W_{\gamma}=$ ca. $1.5 \mathrm{~km}$ and, hence, an observable thickness of 3 to $4.5 \mathrm{~km}$ for a shear zone which is active for $1 \mathrm{Ma}$. For a shear zone which is active for $4 \mathrm{Ma}$ $W_{\gamma}=$ ca. $3 \mathrm{~km}$ and the observable thickness is 6 to $9 \mathrm{~km}$. Since $W_{\gamma}$ only depends on time and is independent on the applied shear velocity it can be applied to any shear velocity and displacement. For example, a shear displacement of $100 \mathrm{~km}$ for a shear velocity of $2.5 \mathrm{~cm} . \mathrm{yr}^{-1}$ requires $4 \mathrm{Ma}$, for which the observable thickness is 6 to $9 \mathrm{~km}$. A shear zone with such thickness, velocity and displacement is likely typical for major lithospheric shear zones related to subduction zones. Such thickness relation only applies to depth levels in the lithosphere for which thermal softening controls the strain localization. These durations of shear zone activity and corresponding predicted shear zone thicknesses agree also with those formed by thermal softening in 2D thermo-mechanical numerical simulations of lithospheric shortening (Jaquet and Schmalholz 2017; Jaquet et al. 2017). Based on the same relationship we expect sub-mm thickness for all shear zones that have been active for less than a few seconds.

If natural shear zones would have been formed by thermal softening with moderate temperature increase of 75 to $150^{\circ} \mathrm{C}$, then there would be no significant temperature variation between the shear zone and its wall rock because natural shear zones are observable due to the significant finite strain variation. This difference 
between finite strain and temperature variation explains why many ductile shear zones do not exhibit a significant observable temperature variation. The lack of a sharp and observable temperature variation, for example expressed by variation in metamorphic grade, is not a sufficient argument against the importance of shear heating and thermal softening.

\subsection{Thermal softening and grain size reduction}

There is still ongoing dispute concerning the primary mechanism of ductile strain localization in the lithosphere. Alternative to thermal softening, grain size reduction in combination with mechanisms, such as pinning, that prohibit grain growth (generally referred to as damage) is often proposed as primary strain localization mechanism. Clearly, in nature both mechanisms act simultaneously. We argue that thermal softening is a suitable mechanism for spontaneous strain localization in essentially homogeneous material whereby only minor heterogeneities can trigger strain localization. Grain size reduction can assist thermal softening and grain size reduction is likely a mechanism that is important during progressive shear zone evolution and can decrease the widening rate of the finite strain profile due to heat conduction. For example, Thielmann et al. (2015) studied numerically the formation of shear zones by thermal runaway using a combined approach of thermal softening and grain size reduction. They showed that grain size reduction reduces the stress required for thermal runaway and hence assists ductile shear zone formation by thermal softening. Currently, different grain size evolution models are applied, for example, Thielmann et al. (2015) apply the so-called paleowattmeter model in which grain size is a function of flow stress, strain rate and temperature, whereas Platt (2015) applies a piezometer in which grain size depends on flow stress only. To reliably quantify the impact of grain size evolution 
better constrained grain size evolution models for various rock types are needed.

\section{Conclusions}

A ductile shear zone which is generated spontaneously by thermal softening during a velocity-driven bulk deformation exhibits the following fundamental features: (1) After a transient period of temperature increase the temperature in the shear zone remains constant for linear viscous flow and quasi-constant for powerlaw viscous flow. (2) The shear stress in the shear zone is largest at the onset of shear zone formation and subsequently decreases towards a (quasi-)constant value associated with the establishment of a (quasi-)constant temperature. (3) The width of temperature variation across the shear zone is 6 to 8 times wider than the variation of the corresponding finite strain. Therefore, the shear zone does not exhibit a sharp, and hence easily observable, temperature variation between highly-strained shear zone and little-strained wall rock. (4) The shear zone is continuously widening during shearing due to thermal conduction between shear zone and wall rock. (5) Shear heating starts to dominate the heat transfer between shear zone and wall rock once the temperature increase in the shear zone is $>$ ca. $50{ }^{\circ} \mathrm{C}$.

Different versions of the Brinkman number can predict the onset of shear zone generation by thermal softening. However, the Brinkman number cannot quantify the temperature increase inside the shear zone and, hence, the intensity of thermal softening. We derived a new analytical formula that predicts the maximal temperature inside the shear zone. This temperature prediction requires only information on the bulk deformation, such as far-field velocity, flow law and thermal parameters, and, therefore, no a priori knowledge of the shear zone itself, such as thickness, flow stress and strain rate. Temperature predictions across the scales of 
geological velocities show first order agreement with several natural shear zones including Alpine basement nappes, eclogite shear zones and pseudotachylites. We show with 1D, 2D and 3D numerical simulations that this temperature prediction is valid for shear zone generation under both bulk simple and pure shear.

Our results indicate that shear zone generation by thermal softening likely occurs during lithosphere deformation in the continental lower crust and the mantle lithosphere for typical lithospheric velocities of few cm. $\mathrm{yr}^{-1}$ or bulk strain rates between $10^{-16}$ and $10^{-14} \mathrm{~s}^{-1}$. For these deformation conditions, shear stresses of few hundred MPa can already cause shear zone generation by thermal softening.

Based on our results and their application to lithospheric flow laws and deformation conditions, we argue that spontaneous shear zone generation by thermal softening is a feasible and likely the primary mechanism for spontaneous lithospheric scale shear zone generation. Thermal softening is probably a key constituent of subduction initiation, for example, at a thinned passive continental margin. Additional processes, such as grain size reduction, fabric development or fluid-related reactions can cause additional softening during progressive shear zone evolution and likely intensify the strain localization.

\section{Acknowledgements}

We thank an anonymous reviewer for constructive and helpful comments. This work was supported by SNF grant No. 200020-149380 and the University of Lausanne. We thank Ludovic Räss for assistance in performing the 3D numerical simulations. 


\section{References}

Aharonov, E., Scholz, C. H., 2018. A physics-based rock friction constitutive law: Steady state friction. Journal of Geophysical Research: Solid Earth 123 (2), 1591-1614.

Andersen, T. B., Mair, K., Austrheim, H., Podladchikov, Y. Y., Vrijmoed, J. C., 2008. Stress release in exhumed intermediate and deep earthquakes determined from ultramafic pseudotachylyte. Geology 36 (12), 995-998.

Bercovici, D., Ricard, Y., 2012. Mechanisms for the generation of plate tectonics by two-phase grain-damage and pinning. Physics of the Earth and Planetary Interiors 202, 27-55.

Bizzarri, A., 2012. Analytical representation of the fault slip velocity from spontaneous dynamic earthquake models. Journal of Geophysical Research: Solid Earth 117 (B6).

Brinkman, H., 1951. Heat effects in capillary flow i. Applied Scientific Research $2(1), 120-124$.

Brown, K. M., Fialko, Y., 2012. 'melt welt'mechanism of extreme weakening of gabbro at seismic slip rates. Nature 488 (7413), 638.

Brun, J., Cobbold, P., 1980. Strain heating and thermal softening in continental shear zones: a review. Journal of Structural Geology 2 (1-2), 149-158.

Carter, N. L., Tsenn, M. C., 1987. Flow properties of continental lithosphere. Tectonophysics 136 (1-2), 27-63. 
Chu, X., Ague, J. J., Podladchikov, Y. Y., Tian, M., 2017. Ultrafast eclogite formation via melting-induced overpressure. Earth and Planetary Science Letters 479, 1-17.

Duretz, T., Räss, L., Podladchikov, Y., Schmalholz, S., 2019. Resolving thermomechanical coupling in two and three dimensions: spontaneous strain localization owing to shear heating. Geophysical Journal International 216 (1), $365-379$.

Duretz, T., Schmalholz, S., Podladchikov, Y., 2015. Shear heating-induced strain localization across the scales. Philosophical Magazine 95 (28-30), 3192-3207.

Duretz, T., Schmalholz, S., Podladchikov, Y., Yuen, D., 2014. Physics-controlled thickness of shear zones caused by viscous heating: Implications for crustal shear localization. Geophysical Research Letters 41 (14), 4904-4911.

Fialko, Y., Khazan, Y., 2005. Fusion by earthquake fault friction: Stick or slip? Journal of Geophysical Research: Solid Earth 110 (B12).

Fleitout, L., Froidevaux, C., 1980. Thermal and mechanical evolution of shear zones. Journal of Structural Geology 2 (1-2), 159-164.

Gerya, T., 2009. Introduction to numerical geodynamic modelling. Cambridge University Press.

Ghazian, R. K., Buiter, S. J., 2013. A numerical investigation of continental collision styles. Geophysical Journal International 193 (3), 1133-1152.

Gruntfest, I., 1963. Thermal feedback in liquid flow; plane shear at constant stress. Transactions of the Society of Rheology 7 (1), 195-207. 
Gueydan, F., Précigout, J., Montési, L. G., 2014. Strain weakening enables continental plate tectonics. Tectonophysics 631, 189 - 196, observational and Modelling perspectives on the Mechanical properties of the Lithosphere.

Hersey, M. D., 1936. Note on heat effects in capillary flow. Physics 7 (11), $403-$ 407.

Herwegh, M., Poulet, T., Karrech, A., Regenauer-Lieb, K., 2014. From transient to steady state deformation and grain size: A thermodynamic approach using elasto-visco-plastic numerical modeling. Journal of Geophysical Research: Solid Earth 119 (2), 900-918.

Hirth, G., Kohlstedt, D., 2003. Rheology of the upper mantle and the mantle wedge: A view from the experimentalists. Inside the subduction Factory, 83105.

Hirth, G., Teyssier, C., Dunlap, J. W., 2001. An evaluation of quartzite flow laws based on comparisons between experimentally and naturally deformed rocks. International Journal of Earth Sciences 90 (1), 77-87.

Jaquet, Y., Duretz, T., Grujic, D., Masson, H., Schmalholz, S. M., 2017. Formation of orogenic wedges and crustal shear zones by thermal softening, associated topographic evolution and application to natural orogens. Tectonophysics.

Jaquet, Y., Duretz, T., Schmalholz, S. M., 2015. Dramatic effect of elasticity on thermal softening and strain localization during lithospheric shortening. Geophysical Journal International 204 (2), 780-784. 
Jaquet, Y., Schmalholz, S. M., 2017. Spontaneous ductile crustal shear zone formation by thermal softening and related stress, temperature and strain rate evolution. Tectonophysics.

Karato, S.-i., 2008. Deformation of Earth Materials: An Introduction to the Rheology of Solid Earth by Shun-ichiro Karato. Cambridge University Press.

Kaus, B. J., Podladchikov, Y. Y., 2006. Initiation of localized shear zones in viscoelastoplastic rocks. Journal of Geophysical Research: Solid Earth 111 (B4).

Keller, L. M., Hess, M., Fügenschuh, B., Schmid, S. M., 2005. Structural and metamorphic evolution of the camughera-moncucco, antrona and monte rosa units southwest of the simplon line, western alps. Eclogae Geologicae Helvetiae $98(1), 19-49$.

Leloup, P. H., Ricard, Y., Battaglia, J., Lacassin, R., 1999. Shear heating in continental strike-slip shear zones: model and field examples. Geophysical Journal International $136(1), 19-40$.

Mako, C. A., Caddick, M. J., 2018. Quantifying magnitudes of shear heating in metamorphic systems. Tectonophysics 744, 499-517.

Mancktelow, N. S., Pennacchioni, G., 2005. The control of precursor brittle fracture and fluid-rock interaction on the development of single and paired ductile shear zones. Journal of Structural Geology 27 (4), 645-661.

Manzotti, P., Bosse, V., Pitra, P., Robyr, M., Schiavi, F., Ballèvre, M., 2018. Exhumation rates in the gran paradiso massif (western alps) constrained by in situ $\mathrm{u}-\mathrm{th}-\mathrm{pb}$ dating of accessory phases (monazite, allanite and xenotime). Contributions to Mineralogy and Petrology 173 (3), 24. 
Montési, L. G., 2013. Fabric development as the key for forming ductile shear zones and enabling plate tectonics. Journal of Structural Geology 50, 254-266.

Moore, J. D., Parsons, B., 2015. Scaling of viscous shear zones with depthdependent viscosity and power-law stress-strain-rate dependence. Geophysical Journal International 202 (1), 242-260.

Nagel, T. J., 2008. Tertiary subduction, collision and exhumation recorded in the adula nappe, central alps. Geological Society, London, Special Publications 298 (1), 365-392.

Omlin, S., 2016. Development of massively parallel near peak performance solvers for three-dimensional geodynamic modelling. Ph.D. thesis, University of Lausanne.

Platt, J., Behr, W., 2011. Grainsize evolution in ductile shear zones: Implications for strain localization and the strength of the lithosphere. Journal of Structural Geology 33 (4), 537-550.

Platt, J. P., 2015. Influence of shear heating on microstructurally defined plate boundary shear zones. Journal of Structural Geology 79, 80-89.

Pozzi, G., De Paola, N., Nielsen, S. B., Holdsworth, R. E., Bowen, L., 2018. A new interpretation for the nature and significance of mirror-like surfaces in experimental carbonate-hosted seismic faults. Geology.

Regenauer-Lieb, K., Yuen, D. A., 1998. Rapid conversion of elastic energy into plastic shear heating during incipient necking of the lithosphere. Geophysical Research Letters 25 (14), 2737-2740. 
Regenauer-Lieb, K., Yuen, D. A., Branlund, J., 2001. The initiation of subduction: criticality by addition of water? Science 294 (5542), 578-580.

Rybacki, E., Dresen, G., 2004. Deformation mechanism maps for feldspar rocks. Tectonophysics 382 (3), 173-187.

Schmalholz, S., Duretz, T., 2015. Shear zone and nappe formation by thermal softening, related stress and temperature evolution, and application to the alps. Journal of Metamorphic Geology 33 (8), 887-908.

Sibson, R. H., 1975. Generation of pseudotachylyte by ancient seismic faulting. Geophysical Journal International 43 (3), 775-794.

Takeuchi, C. S., Fialko, Y., 2012. Dynamic models of interseismic deformation and stress transfer from plate motion to continental transform faults. Journal of Geophysical Research: Solid Earth 117 (B5).

Thielmann, M., Kaus, B. J., 2012. Shear heating induced lithospheric-scale localization: Does it result in subduction? Earth and Planetary Science Letters 359, $1-13$.

Thielmann, M., Rozel, A., Kaus, B., Ricard, Y., 2015. Intermediate-depth earthquake generation and shear zone formation caused by grain size reduction and shear heating. Geology 43 (9), 791-794.

Versteeg, H., Malalasekra, W., 2007. An Introduction to Computational Fluid Dynamics: The Finite Volume Method (2nd Edition). Pearson.

White, S. t., Knipe, R., 1978. Transformation-and reaction-enhanced ductility in rocks. Journal of the Geological Society 135 (5), 513-516. 
${ }_{724}$ Yuen, D., Fleitout, L., Schubert, G., Froidevaux, C., 1978. Shear deformation 725 zones along major transform faults and subducting slabs. Geophysical Journal 726 International 54 (1), 93-119. 


\begin{tabular}{|c|c|c|c|c|c|c|c|c|}
\hline Lithology & $A\left[\mathrm{~Pa}^{-(\mathrm{n}+\mathrm{r})} \mathrm{s}^{-1}\right]$ & $\mathrm{n}$ & $f_{\mathrm{H}_{2} \mathrm{O}}[\mathrm{Pa}]$ & $\mathrm{r}$ & $A_{\text {eff }}\left[\mathrm{Pa}^{-\mathrm{n}} \mathrm{s}^{-1}\right]$ & $Q\left[\mathrm{~J} \cdot \mathrm{mol}^{-1}\right]$ & $\lambda\left[\mathrm{W} \cdot \mathrm{K}^{-1} \cdot \mathrm{m}^{-1}\right]$ & $\rho\left[\mathrm{kg} \cdot \mathrm{m}^{-3}\right]$ \\
\hline Wet quartzite ${ }^{1}$ & $6.31 \times 10^{-42}$ & 4.0 & $3.7 \times 10^{7}$ & 1 & $2.91 \times 10^{-32}$ & $1.35 \times 10^{5}$ & 2.5 & 2700 \\
\hline Westerly granite $^{2}$ & $3.17 \times 10^{-26}$ & 3.3 & - & 0 & $1.67 \times 10^{-24}$ & $1.87 \times 10^{5}$ & 2.5 & 2700 \\
\hline Wet albite ${ }^{3}$ & $2.51 \times 10^{-15}$ & 3.0 & - & 0 & $9.04 \times 10^{-14}$ & $3.32 \times 10^{5}$ & 2.2 & 2900 \\
\hline Wet anorthite ${ }^{3}$ & $3.98 \times 10^{-16}$ & 3.0 & - & 0 & $1.43 \times 10^{-14}$ & $3.56 \times 10^{5}$ & 2.2 & 2900 \\
\hline Dry anorthite ${ }^{3}$ & $5.01 \times 10^{-6}$ & 3.0 & - & 0 & $1.80 \times 10^{-4}$ & $6.56 \times 10^{5}$ & 2.2 & 2900 \\
\hline Wet olivine ${ }^{4}$ & $5.68 \times 10^{-27}$ & 3.5 & $10^{9}$ & 1.2 & $2.40 \times 10^{-14}$ & $4.80 \times 10^{5}$ & 3.0 & 3400 \\
\hline Dry olivine $^{4}$ & $1.10 \times 10^{-16}$ & 3.5 & - & 0 & $7.37 \times 10^{-15}$ & $5.30 \times 10^{5}$ & 3.0 & 3400 \\
\hline
\end{tabular}

Table 1: Rheological and thermal parameters for the used lithologies. $A_{\text {eff }}=F A f_{\mathrm{H}_{2} \mathrm{O}}^{r} d^{-p}$ is an effective pre-exponential factor (' $A$ ' in the main text) that incorporates grain size (d) and water fugacity $\left(f_{\mathrm{H}_{2} \mathrm{O}}\right)$ dependence. In all cases we use dislocation creep therefore the grain size exponent is $p=0$. All of these flow laws describe stress and strain rate relationship in uniaxial compression experiments. In order to convert them into strain rate dependent invariant forms we need to introduce a geometry factor, which is $F=2^{n-1} 3^{(n+1) / 2}$ for all presented cases (see e.g. Gerya 2009). The rest of the parameters are: power law exponent (n), water fugacity exponent (r), activation energy (Q), thermal conductivity $(\lambda)$, density $(\rho)$ and finally heat capacity is constant for all $\left(\mathrm{c}_{p}=\right.$ $1050 \mathrm{~J} . \mathrm{kg}^{-1} \mathrm{~K}^{-1}$ ). The sources of the rheological parameters are: ${ }^{1}$ Hirth et al. 2001, ${ }^{2}$ Carter and Tsenn 1987, ${ }^{3}$ Rybacki and Dresen 2004, ${ }^{4}$ Hirth and Kohlstedt 2003. 

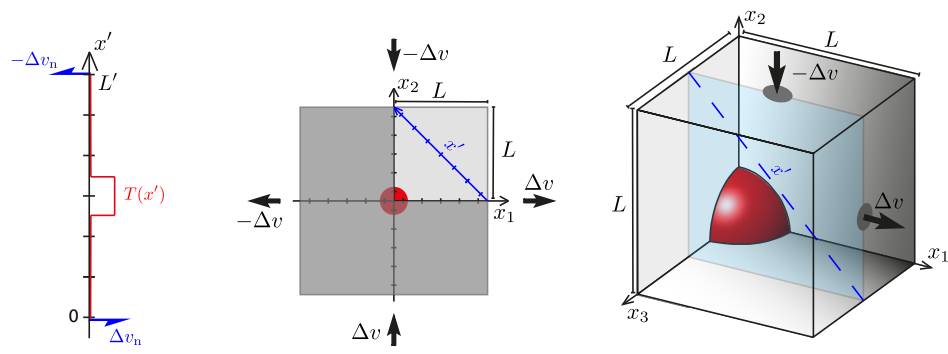

Figure 1: Model configurations for 1D simple shear, and 2D and 3D pure shear bulk deformation. In all models a thermal perturbation (red) is in the model center. Due to the symmetry of the problem we solve the 2D and 3D models only for the positive coordinate region. To compare 1D results with $2 \mathrm{D}$ and $3 \mathrm{D}$ results, the results of the $1 \mathrm{D}$ model are rotated so that they correspond to the direction $\mathrm{x}^{\prime}$ in the 2D and 3D models which is orthogonal to the shear zone. 

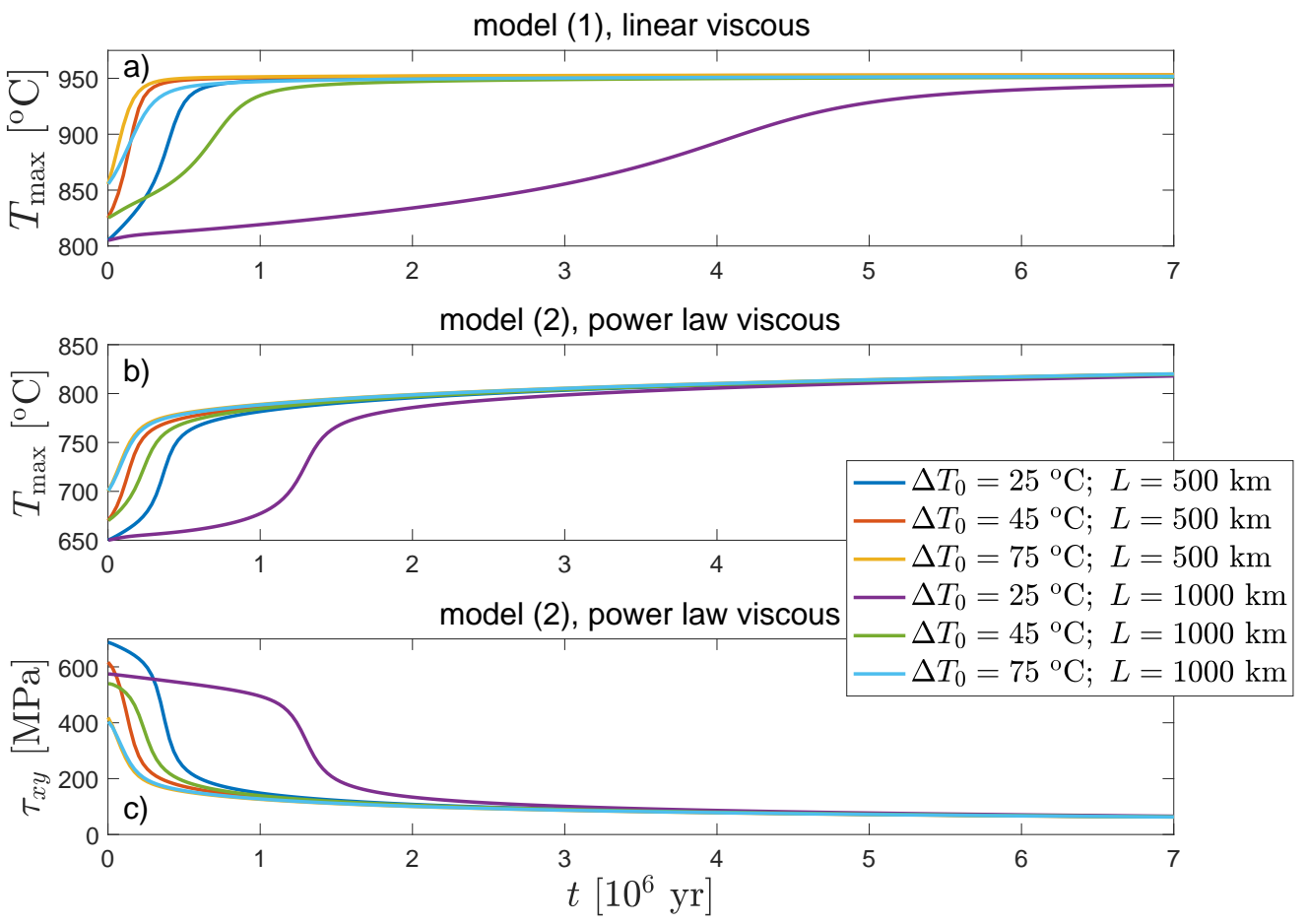

Figure 2: Representative results of 1D shear zone models. Time evolution of maximum temperature at the shear zone center for linear viscous (a) and power-law viscous (b) flow. Model (1) is based on a dry anorthite diffusion creep flow law with $A_{\text {eff }}=0.14 \mathrm{~Pa}_{\mathrm{s}} \mathrm{s}^{-1}(d=0.3 \mathrm{~mm})$ and $Q=$ $467 \mathrm{~kJ} \cdot \mathrm{mol}^{-1}$, model (2) is based on a dry peridotite flow law (see Table 1). In both models we applied $3 \mathrm{~cm} . \mathrm{yr}^{-1}$ velocity difference. Different lines correspond to models with different model size and initial perturbation (see legend, which applies to all three panels). After a transient stage the maximum temperature converges to a constant (a) or (quasi-)constant (b) temperature. c) Shear stress evolution for power law simulations, shown in panel b). The shear stress always decreases with progressive shear zone evolution and converges to a quasi-constant value. 

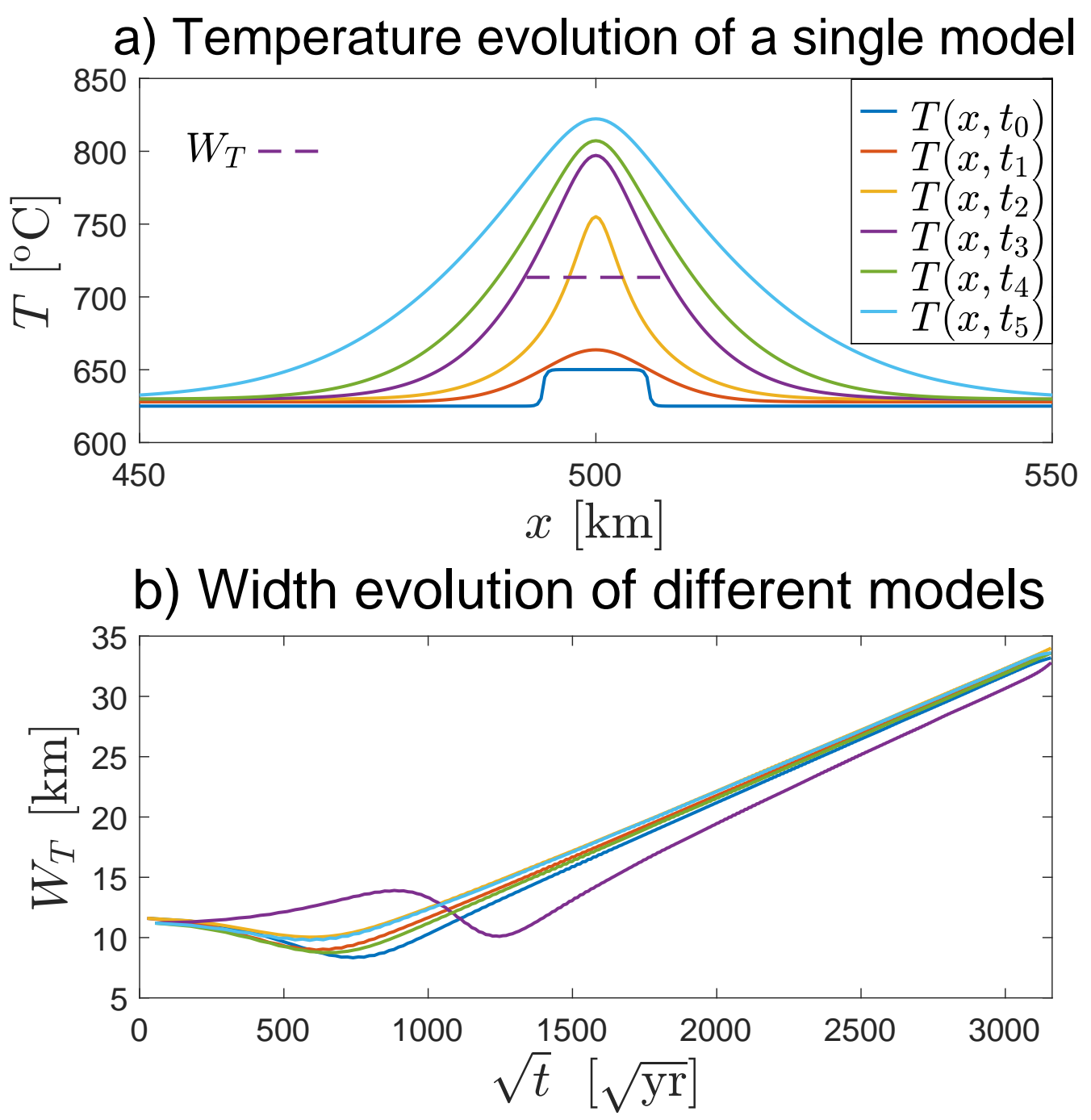

Figure 3: a) Representative time evolution of a temperature profile during shear zone formation. The model setup is equivalent with the one of the $\Delta T_{0}=25{ }^{\circ} \mathrm{C}$, and $\mathrm{L}=1000 \mathrm{~km}$ from Fig. $2 \mathrm{~b}$ and $2 \mathrm{c}$. The dashed horizontal line indicates the thermal thickness which is measured at the temperature which is half between the maximum and minimum temperature of the corresponding profile. b) Evolution of thermal thickness for different representative simulations (same colors are used in Fig. $2 \mathrm{~b}$ and $2 \mathrm{c}$ ). Each line shows the result of a simulation with different initial temperature perturbation and model size. After a transient period, the thickness evolution for all simulations is linearly increasing with the square root of time. 

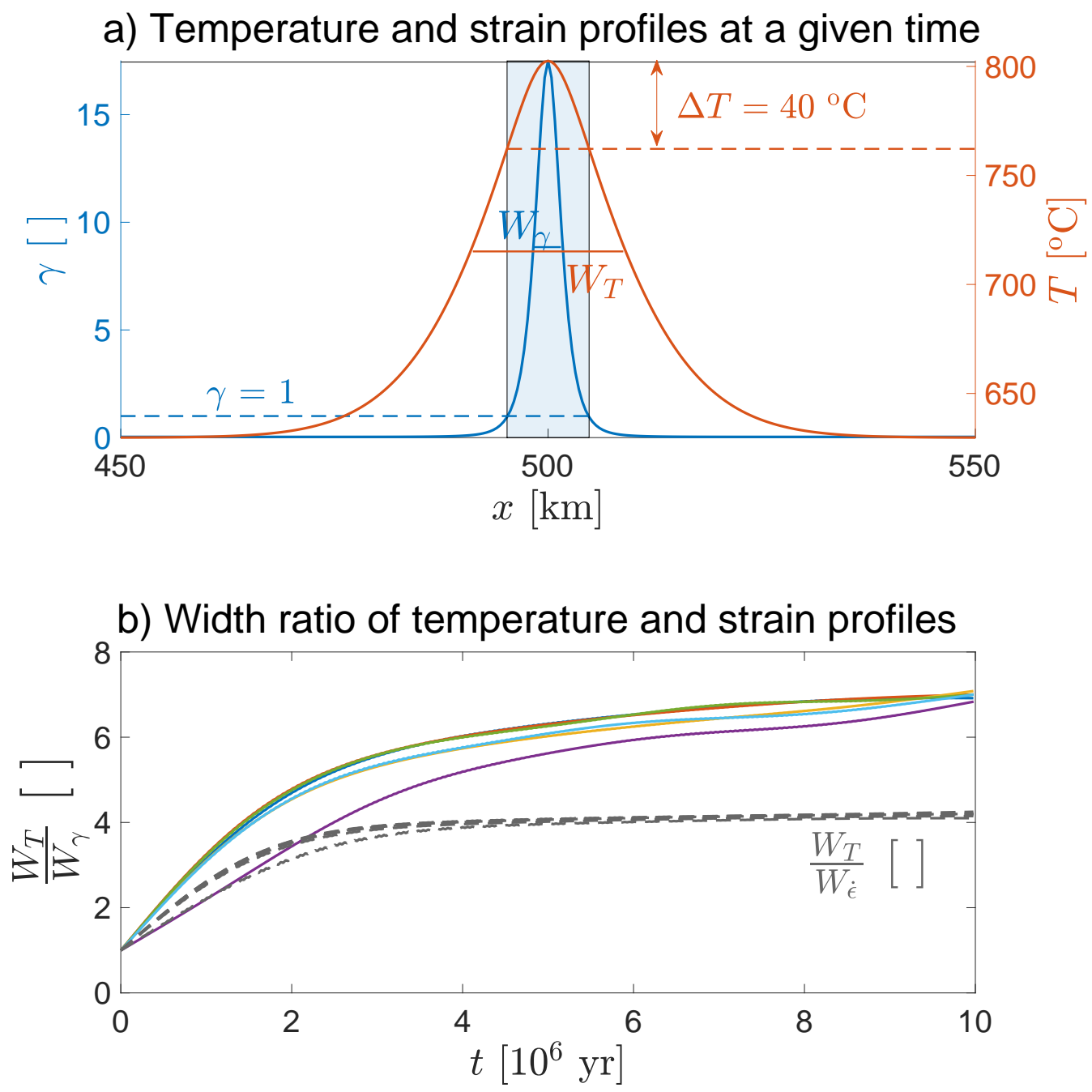

Figure 4: a) Temperature and corresponding finite strain profile for a simulation with a dry olivine flow law after 3.5 Myr. The model setup is equivalent with the one of the $\Delta T_{0}=25^{\circ} \mathrm{C}$, and $\mathrm{L}=$ $1000 \mathrm{~km}$ from Fig. 2b and 2c. The temperature profile is significantly wider than the finite strain profile. The thickness of both profiles is measured at the vertical value which is half between the maximum and minimum value of the profile. b) Evolution of the ratio of thermal thickness to corresponding finite strain thickness with progressive time for different model configurations (colors are corresponding to Fig. $2 \mathrm{~b}$ and $2 \mathrm{c}$ ). After a transient stage the ratios approach values between 6 and 8 showing that the temperature variation is nearly one order of magnitude wider than the corresponding finite strain variation. For comparison, also the ratio of thermal thickness to corresponding instantaneous strain rate thickness is displayed with gray dashed lines, because this thickness ratio is constant and ca. 4 for all shown simulations. 


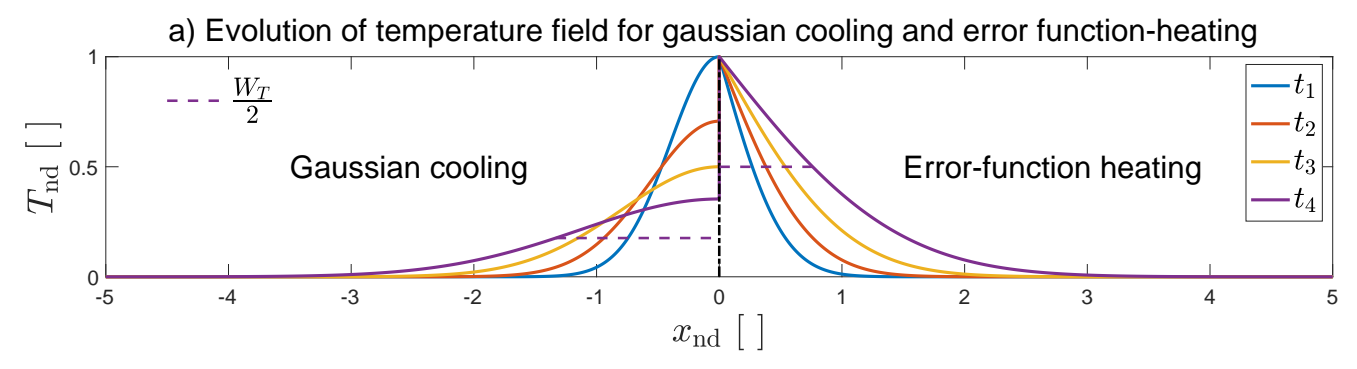

b) Dimensionless width of different simulations

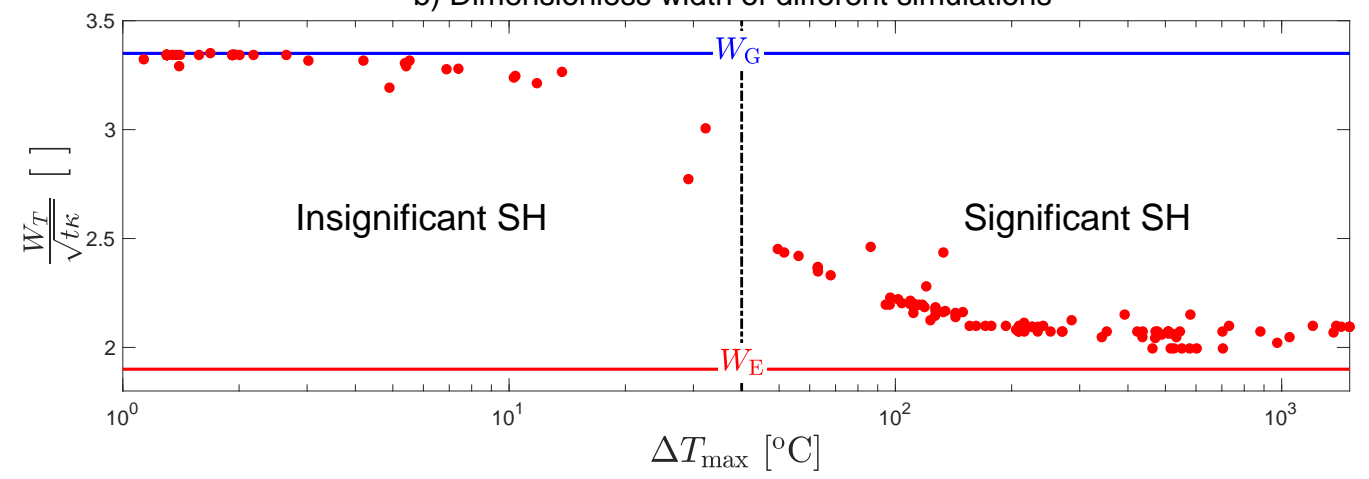

Figure 5: a) Representative temperature evolution for cooling of an initial Gaussian temperature profile, left curves, and for heating for a constant temperature in the model center, right curves. Lines for $t_{1}$ to $t_{4}$ display temperature profiles at progressive times. The dashed horizontal lines indicate the half-width of a specific temperature profile. Horizontal $\mathrm{x}$-coordinates and temperatures are dimensionless and temperatures have been scaled so that the initial temperature is identical. b) Plot of the dimensionless widths of temperature profiles determined from 1D numerical simulations versus the corresponding temperature increase in the shear zone centre, $\Delta T_{\max }$. The blue and red horizontal lines indicate the theoretical dimensionless width for cooling of an initial Gaussian temperature profile (equation 13) and for heating for a constant temperature in the shear zone (equation 16), respectively. A value of $\Delta T_{\max } \approx 40^{\circ} \mathrm{C}$ indicates the transition between the two types of heat transfer and for $\Delta T_{\max }>40^{\circ} \mathrm{C}$ shear heating (SH) is significant. 

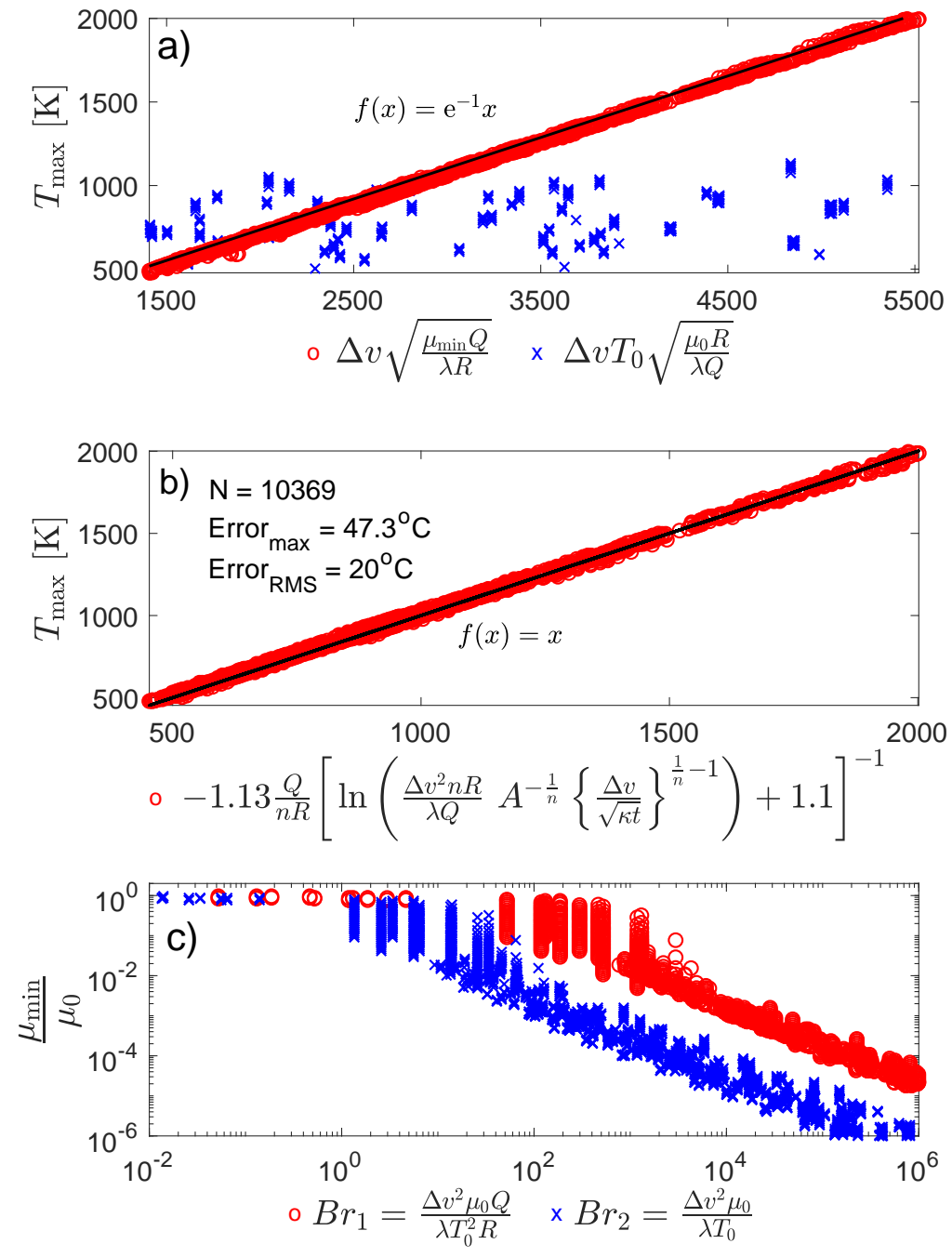

Figure 6: a) Maximum temperature versus two different characteristic temperatures for all 1D simulations. Red circles represent a choice of scales which generates a data collaps and the blue crosses are an example of a scaling that generates a data scatter. The black line indicates a fit of the data (see equation in panel) where e is the Euler number. b) Maximum temperature in the shear zone from all numerical 1D simulations $\left(T_{\max }\right)$ versus the maximum temperature predicted with equation 22 (equation in label). c) Ratio of the minimum shear zone viscosity to the initial viscosity versus two versions of Brinkman number, $B r_{1}$ and $B r_{2}$. 
a) $\Delta T$ in a $3 \mathrm{D}$ model at $t_{1}$

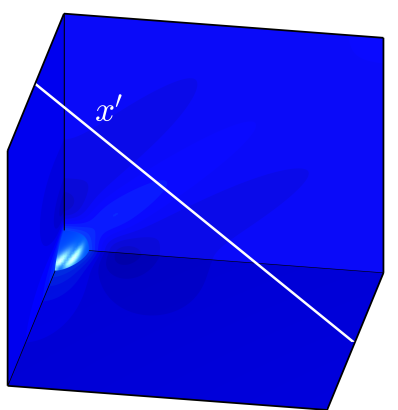

d) $\Delta T$ in a $2 \mathrm{D}$ model at $t_{1}$
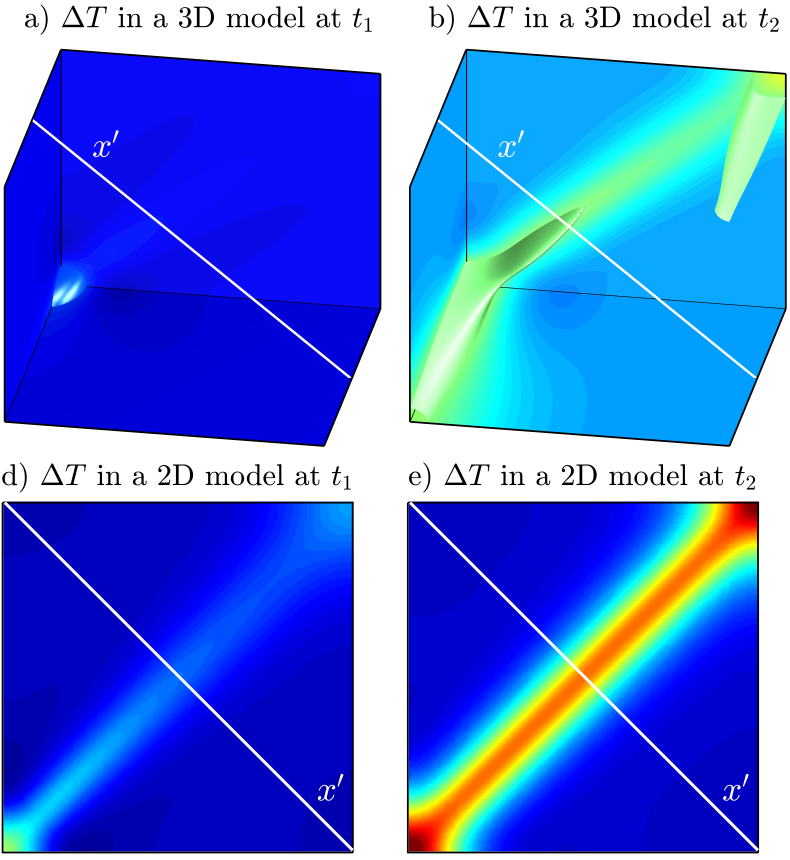

e) $\Delta T$ in a $2 \mathrm{D}$ model at $t_{2}$

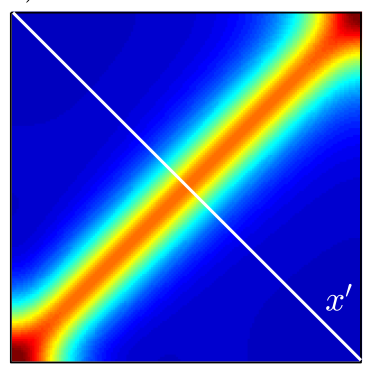

Comparison of $\Delta T$ along $x^{\prime}$
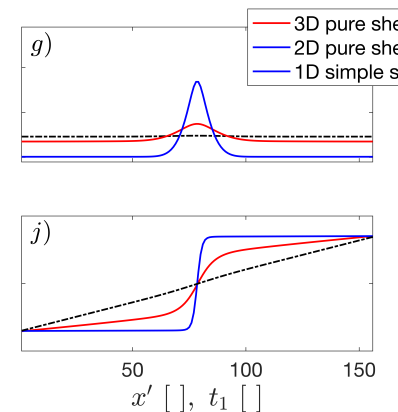

Comparison of $v_{\text {normal }}$ along $x^{\prime}$

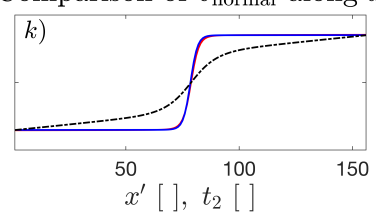

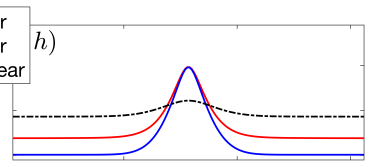

c) $\Delta T$ in a $3 \mathrm{D}$ model at $t_{3}$

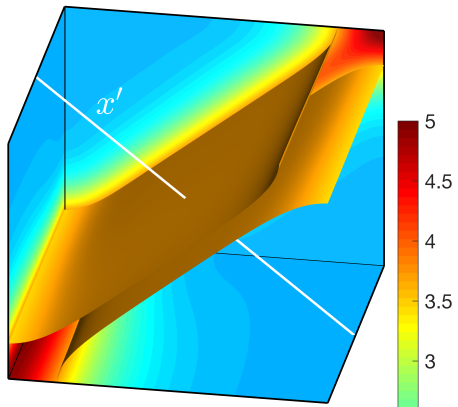

f) $\Delta T$ in a $2 \mathrm{D}$ model at $t_{3} \quad-2.5$
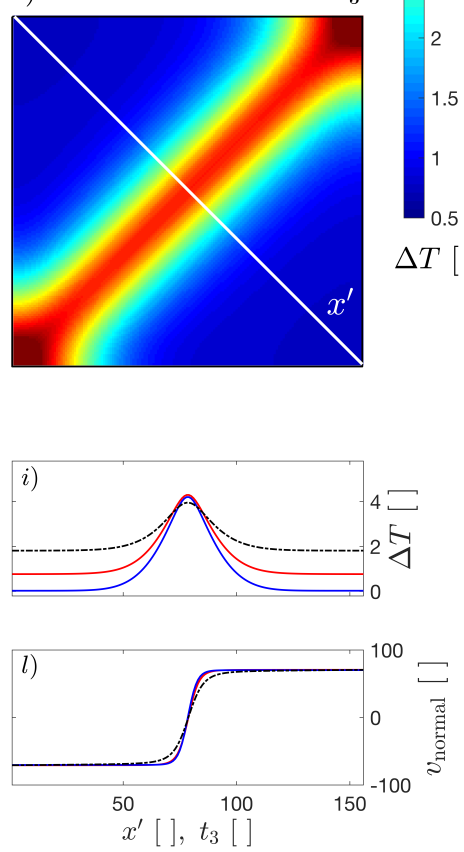

Figure 7: Comparison of temperature and velocity profiles across 1D, 2D and 3D shear zones. a) to c) shows the temperature field for three stages of 3D shear zone formation. d) to f) shows the temperature field for three stages of $2 \mathrm{D}$ shear zone formation. The profile lines indicated with $x^{\prime}$ in both 2D and 3D models are used for the comparison with the 1D model. g) to i) show 1D temperature profile and the $2 \mathrm{D}$ and $3 \mathrm{D}$ profiles along the $x^{\prime}$ profile for three different times. $\mathrm{j}$ ) to 1) show the $1 \mathrm{D}$ velocity profile and the $2 \mathrm{D}$ and $3 \mathrm{D}$ profiles along the $x^{\prime}$-profile for three different times. The displayed velocity magnitudes are normal to the profile orientation and, hence, parallel to the shear zone orientation. 


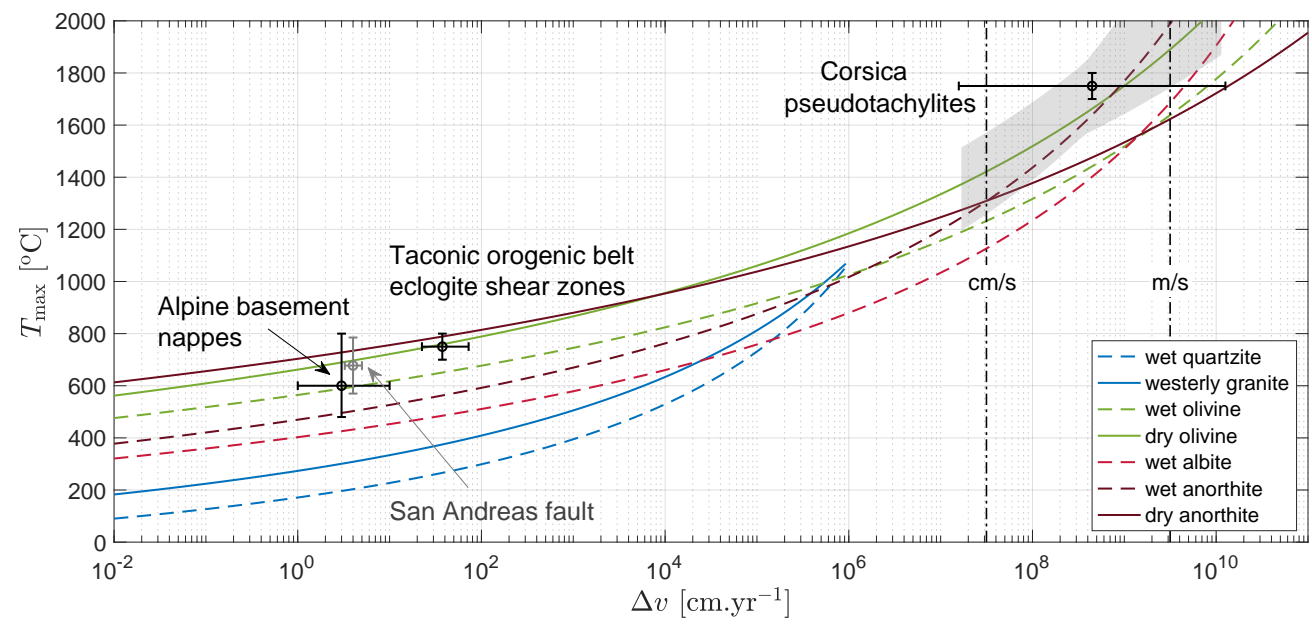

Figure 8: Predicted maximum temperature in shear zones across the scales. Four data points are shown as possible applications. Three of them are direct observations, displayed with black, while the gray is an indirect observation (see in section 6). Equation 22 is used for temperature prediction versus the applied boundary velocities, $\Delta v$, for different flow laws (see legend and Table 1). The same constant finite shear strain, $\gamma_{c}=20$, is assumed for all shear zones and the corresponding duration of the deformation is calculated with equation 26. For pseudotachylites the typical values of finite strain are higher. The expected temperature range for $\gamma_{\mathrm{c}}=80$ is indicated by the light gray area. The quartzite flow laws are not displayed for high velocities because for those the argument of the logarithm is approaching $\exp (-1.1) \approx 0.3$, where the prediction starts to significantly deviate from the solution. 


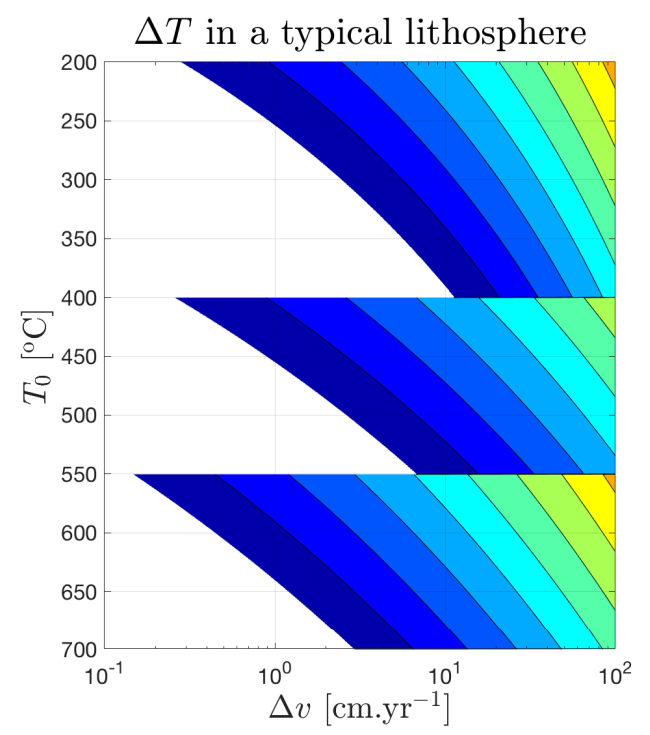

$\Delta T$ in an extended lithosphere
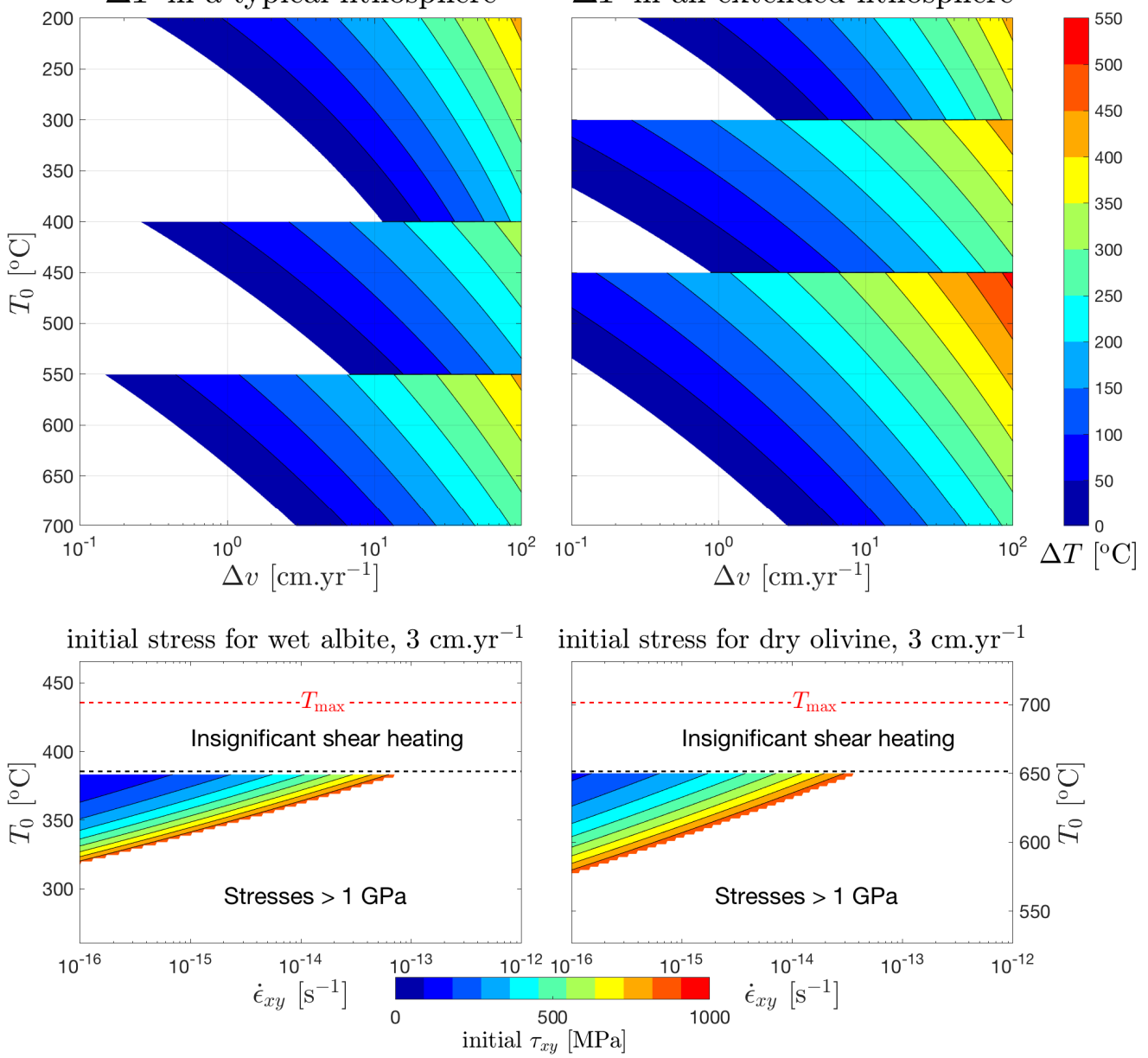

Figure 9: a) and b) show color plots of the temperature difference, $\Delta T$, between the maximum temperature predicted with equation (22) and the initial temperature, $T_{0}$, corresponding to the ambient temperature at a certain depth in the lithosphere. $\Delta T$ is contoured for different values of $T_{0}$ and $\Delta V . \Delta T$ is calculated for a deformation time of $1 \mathrm{Ma}$. The three regions in the color plots correspond to three different flow laws, namely for Westerly granite (top region representing upper crust), wet anorthite (middle region representing lower crust) and wet olivine (lower region representing mantle lithosphere). c) and d) show color plots of the initial shear stress in 1D simulations as a function of $T_{0}$ and applied bulk strain rate, $\dot{\epsilon}_{x y}$. c) shows results for wet albite flow law and d) for dry olivine. The applied velocity difference is $3 \mathrm{~cm} \cdot \mathrm{yr}^{-1}$ and bulk strain rates are modified by changing the 1D model size. The red dashed horizontal line indicates the maximum temperature, $T_{\max }$, from equation (22). To have significant shear localization, $T_{0}$ must be at least $50{ }^{\circ} \mathrm{C}$ smaller than $T_{\max }$ (see Fig. $5 \mathrm{~b}$ ). Only shear stresses $<1 \mathrm{GPa}$ are displayed. The colored regions in c) and d) indicate the "window" in which shear zone generation by thermal softening is feasible in the lower crust (c) and mantle lithosphere (d). 